\title{
Synthesis and Computational Characterization of Organic UV-Dyes for Cosensitization of Transparent Dye-Sensitized Solar Cells
}

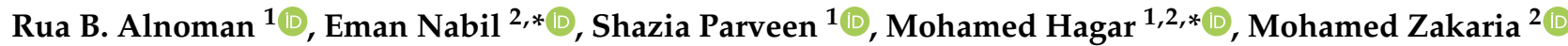 \\ and Ahmed A. Hasanein ${ }^{2}$ \\ 1 Department of Chemistry, Faculty of Science, Taibah University, Yanbu 4642, Saudi Arabia; \\ rua-b-n@live.co.uk (R.B.A.); shazia021@gmail.com (S.P.) \\ 2 Department of Chemistry, Faculty of Science, Alexandria University, Alexandria 21321, Egypt; \\ m.zak_8770@hotmail.com (M.Z.); Ahemedhasanein@Alexu.edu.eg (A.A.H.) \\ * Correspondence: eman.nabil@alexu.edu.eg (E.N.); Mohamedhaggar@gmail.com (M.H.)
}

check for updates

Citation: Alnoman, R.B.; Nabil, E.; Parveen, S.; Hagar, M.; Zakaria, M.; Hasanein, A.A. Synthesis and Computational Characterization of Organic UV-Dyes for Cosensitization of Transparent Dye-Sensitized Solar Cells. Molecules 2021, 26, 7336. https://doi.org/10.3390/ molecules26237336

Academic Editors: Mariachiara Pastore and Barbara Panunzi

Received: 11 October 2021

Accepted: 25 November 2021

Published: 3 December 2021

Publisher's Note: MDPI stays neutral with regard to jurisdictional claims in published maps and institutional affiliations.

Copyright: (c) 2021 by the authors. Licensee MDPI, Basel, Switzerland. This article is an open access article distributed under the terms and conditions of the Creative Commons Attribution (CC BY) license (https:/ / creativecommons.org/licenses/by/ $4.0 /)$.

\begin{abstract}
The fabrication of colorless and see-through dye-sensitized solar cells (DSCs) requires the photosensitizers to have little or no absorption in the visible light region of the solar spectrum. However, a trade-off between transparency and power conversion efficiency (PCE) has to be tackled, since most transparent DSCs are showing low PCE when compared to colorful and opaque DSCs. One strategy to increase PCE is applying two cosensitizers with selective conversion of the UV and NIR radiation, therefore, the non-visible part only is absorbed. In this study, we report synthesis of novel five UV-selective absorbers, based on diimide and Schiff bases incorporating carboxyl and pyridyl anchoring groups. A systematic computational investigation using density functional theory (DFT) and time-dependent DFT approaches was employed to evaluate their prospect of application in transparent DSCs. Experimental UV/Vis absorption spectra showed that all dyes exhibit an absorption band covering the mid/near-UV region of solar spectrum, with a bathochromic shift and a hyperchromic shifts for Py-1 dye. Computational results showed that the studied dyes satisfied the basic photophysical and energetics requirements of operating DSC as well as the stability and thermodynamical spontaneity of adsorption onto surface of $\mathrm{TiO}_{2}$. However, results revealed outperformance of the thienothiophene core-containing Py-1 UV-dye, owing to its advantageous structural attributes, improved conjugation, intense emission, large Stokes shift and maximum charge transferred to the anchor. Chemical compatibility of Py-1 dye was then theoretically investigated as a potential cosensitizer of a reference VG20-C2 NIR-dye. By the judicious selection of pyridyl anchorbased UV-absorber (Py-1) and carboxyl anchor-based NIR-absorber (VG20), the advantage of the optical complementarity and selectivity of different $\mathrm{TiO}_{2}$-adsorption-site (Lewis- and Bronsted-acidic) can be achieved. An improved overall PCE is estimated accordingly.
\end{abstract}

Keywords: dye-sensitized solar cells; computational characterization; organic UV-dyes; cosensitization

\section{Introduction}

One of the emerging environmental technologies is building integrated (BI) solarpowered windows, with built-in solar panels, for converting sunlight into electricity [1] Dye-sensitized solar cell (DSC) is one of the eco-friendly sources of solar energy that has a great potential to be applied in solar windows owing to its high average visible transmittance (AVT) and ability to operate in poor or ambient sunlight conditions [2-4]. Inspired by the crucial role of chlorophyll in the photosynthesis process, O'Regan and Grätzel reported first DSC device using fabrication process called "sensitization" of mesoporous titanium oxide $\left(\mathrm{TiO}_{2}\right)$ film using photosensitizer (dye) [5]. In DSCs, the sensitizer that adsorbs chemically to the semiconductor is the accountable component of capturing and converting light energy. The photoelectron transport in such solar cells can be divided into 
four steps [6]: (1) excitation of dye molecules through light absorption; (2) subsequently injection of photo-excited electrons into the conduction band $(C B)$ of the semiconductor (frequently $\left.\mathrm{TiO}_{2}\right)$; (3) oxidized dye molecules obtain electrons from redox couple: $\left(\mathrm{I}^{-} / \mathrm{I}_{3}{ }^{-}\right.$ or $\left.\mathrm{Co}^{3+} / \mathrm{Co}^{2+}\right)$ so that regeneration of dye is achievable; (4) reduction of the oxidized redox mediator at the counter electrode to complete the circuit. Yet, during the operating cycle of DSCs, there are unwanted competing loss pathways leading to lower overall power conversion efficiency (PCE) of the device. Namely, decay of the excited dye to the ground state and recombination of the injected electrons in the $C B$ of semiconductor with the adsorbed oxidized dye molecules or with ions in the electrolyte solution [7].

Cosensitization of the semiconducting electrode, with two or more photosensitizers with complementary absorption spectra, is the direct solution to overcome the partial absorption coverage of solar emission spectrum resulted from using single sensitizer [8]. For achieving a panchromatic absorption spectrum in traditional opaque cosensitized DSC (co-DSC) systems, opaque absorbers (cosensitizers) are required to cover the entire visible region and extend toward the near-infrared (NIR) region of solar spectrum.

In contrast, transparent and colorless co-DSCs/DSCs devices require a selective conversion of the UV and/or NIR regions of the solar spectrum through which only the nonvisible part of the solar spectrum is converted into electricity [9]. Since the human eye typically responds to visible light from 400 to $700 \mathrm{~nm}$, cosensitizers should have little or no absorption in the visible light region with high human eye sensitivity $(500-600 \mathrm{~nm})$. In DSCs, tailoring the coloration and level of transparency can be achieved by modulating the absorption range of photosensitizers and the electrode thickness. Thickness of electrode can be controlled by employing sensitizers with high molar extinction coefficients which permit the fabrication of DSCs with thinner $\mathrm{TiO}_{2}$ films [10]. In solar-powered windows, $\mathrm{TiO}_{2}$ layer is supposed to be sufficiently thin in order to not be seen. Indeed, previous work in organic and organometallic DSCs has shown ongoing progress in the development of transparent solar cells. A see-through DSC, with over 10\% efficiency, was proposed by Wang et al., who fabricated a semitransparent cell using donor-acceptor thienochrysenocarbazole-based organic dyes with experimental absorption maximum $\left(\lambda_{\max }\right)$ of 562 to $582 \mathrm{~nm}$ in toluene solvent [11]. Similarly, Yuan et al. employed donor-acceptor organic dyes for fabrication of goldenrod, crimson, red, and sapphire blue semitransparent cells with power conversion efficiencies of $3.5 \%, 8.2 \%, 7.6 \%$, and $10.1 \%$, respectively [12]. Light-driven adjustable optical transmission due to photochromic sensitizers was proposed by Demadrille et al., who achieved a maximum PCE of up to $4.17 \%$ while exhibiting a reversible change of color under irradiation [13]. Earlier, Han et al. reported a semitransparent DSC based on a UV/NIR cosensitization system. The green-colored see-through DSC was fabricated with Y1 and HSQ5 cosensitizers, taking the advantage of the dyes' strong absorptions in 400 and $700 \mathrm{~nm}$, respectively, which are low-eye-sensitivity regions [14]. The most remarkable achievement was recently reported by Sauvage et al., who were able to fabricate fully transparent and colorless DSCs by considering the human eye photopic response to optimize NIR absorbing dyes [15]. The reported UV-Vis spectra of theses NIR-selective dyes have strong and sharp absorption peak beyond $800 \mathrm{~nm}$ due to S0-S1 electronic transition. Dyes are based on symmetrical polymethine cyanine, coded VG20-Cx, with $\mathrm{x}$ values varying from 2 to 16 carbons on the alkyl chain, and the authors reported PCE of $3.1 \%$ and a maximum of $76 \%$ average visible transmittance. Diimides, which are part of a larger class of molecules known as rylenes dye, come in symmetrical and asymmetrical forms, depending on how they're made [16]. Tunable features of diimides-based derivatives include quantum yields of near-unity fluorescence [17], and strong electron-accepting properties enable them to be employed as industrial colorants, both as dyes (soluble) and pigments (insoluble) [18], for the manufacturing of soft electrical devices [19] and organic electronics [20]. The imine or azomethine $(-\mathrm{C}=\mathrm{N}-)$ functional group is found in Schiff bases. Hugo Schiff $[21,22]$ described these as the condensation products of primary amines with carbonyl compounds for the first time. Schiff bases are a type of organic chemicals that has a wide range of uses in a variety of domains, including analytical, biological, and 
inorganic chemistry [23]. In this context, we report synthesis of five new symmetrical UV-selective organic dyes based on diimide (CA-1) and azomethine (CA-2, Py-1, Py-2 and Py-3). Subsequently, quantum chemical computations were performed to investigate their potential application as photosensitizers in DSCs and as promising cosensitizers of the NIR-selective VG20- $C_{2}$ dye, reported by Sauvage et al. [15]. First, density functional theory (DFT) combined with time-dependent density functional theory (TD-DFT) calculations, were performed to qualitatively (or even quantitatively) examine the electrochemical and photophysical properties of the five new organic dyes matching the requirements for efficient DSCs. Secondly, the promising dye is shortlisted for testing as cosensitizer with the VG20- $C_{2}$ dye. For efficient cosensitization, additional requirements are to be considered, namely chemical compatibility between cosensitizers and complementarity of their absorption spectra. This screen suggests the judicious choice of the UV-selective Py-1 dye as a very promising cosensitizer of the NIR-selective VG20- $C_{2}$ dye. Such a strategy of cosensitization between UV and NIR dyes, aims for selectively harvesting light in the invisible region while transmitting light in the visible region. Hence, it should provide a rational approach to enhance overall PCE, and in the meantime retain fully transparency of DSCs for photovoltaic (PV) windows applications.

\section{Methodology}

\subsection{Experimental Methods and Materials} Scheme 1:

The compounds under investigation have been synthesized according to the following

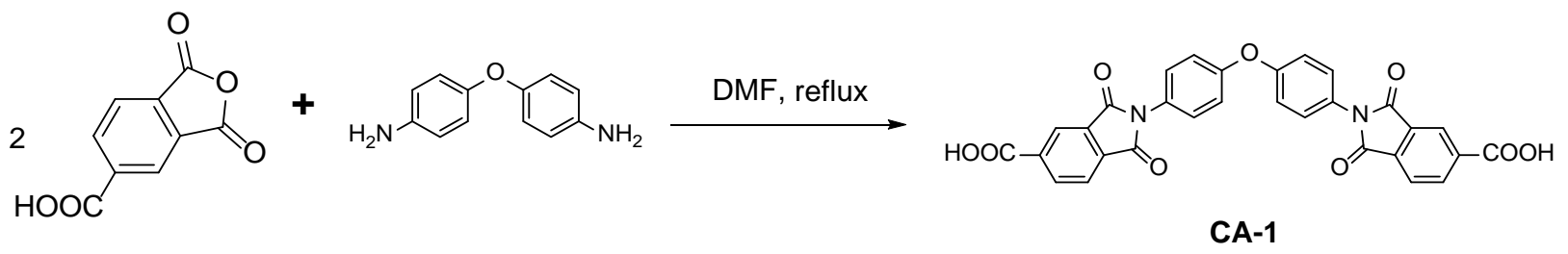

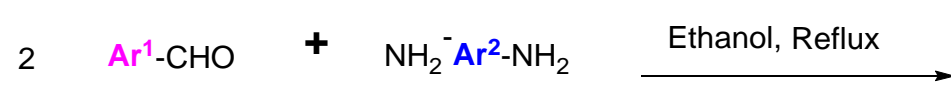

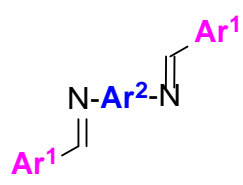

$\mathrm{CA}-2, \mathrm{Ar}^{1}=$<smiles>Cc1ccc(C(=O)O)cc1</smiles>

Py-1, $\mathrm{Ar}^{1}=$<smiles>Cc1ccncc1</smiles>

Py-2, $\operatorname{Ar}^{1}=$<smiles>Cc1ccncc1</smiles>

Py-3, $\mathrm{Ar}^{1}=$<smiles>Cc1ccncc1</smiles><smiles></smiles>

$\mathrm{Ar}^{2}=$<smiles>Cc1cc2sc(C)cc2s1</smiles><smiles>Cc1ccc(Oc2ccc(C)cc2)cc1</smiles>

$\mathrm{Ar}^{2}=$<smiles>Cc1ccc(C)s1</smiles>

Scheme 1. Synthesis of diimide CA-1 and Schiff bases CA-2 and Py-1-3. 


\subsubsection{General Procedure of the Synthesis of Diimide CA-1}

In DMF (5 mL), a mixture of 1,2,4-benzenetricarboxylic anhydride $(0.34 \mathrm{mmol})$ and aromatic diamine $(0.17 \mathrm{mmol})$ was refluxed for $6-8 \mathrm{~h}$ according to the TLC (hexane-ethyl acetate, 1:10). The reaction mixture was allowed to cool; then filtrated to collect the precipitate, which was subsequently recrystallized from DMF

\subsubsection{General Procedure of the Synthesis of Schiff Bases CA-2 and Py-1-3}

Equimolar amount of aryldialdehyde $(4.1 \mathrm{mmol})$ and arylamine $(8.2 \mathrm{mmol})$ in ethanol $(10 \mathrm{~mL})$ were refluxed for two hours. The reaction mixture was allowed to cool and the separated product filtered. The obtained solid was recrystallized from ethanol.

2,2'-[Oxybis(1,4-phenylene)]bis(1H-isoindole-1,3(2H)-dione-5-carboxylic acid), (CA-1). Yield $75 \%$, m.p. $>300^{\circ} \mathrm{C}$, FTIR $\left(\mathrm{KBr}, \mathrm{cm}^{-1}\right)$ : 3525-2810 (m, br, COOH), $1780(\mathrm{C}=\mathrm{O}), 1730(\mathrm{C}=\mathrm{O})$, $1608(\mathrm{C}=\mathrm{C}) .{ }^{1} \mathrm{HNMR}\left(500 \mathrm{MHz}, \mathrm{DMSO}-d_{6}\right), \delta: 10.01(\mathrm{~s}, 2 \mathrm{H}, \mathrm{OH}), 8.65(\mathrm{~s}, 1 \mathrm{H}), 8.43(\mathrm{~s}, 1 \mathrm{H})$, $7.98(\mathrm{~d}, J=8.5 \mathrm{~Hz} 4 \mathrm{H}), 7.70(\mathrm{~d}, J=8.5 \mathrm{~Hz} 4 \mathrm{H}), 7.58-7.47(\mathrm{~m}, 2 \mathrm{H}), 7.40-7.20(\mathrm{~m}, 2 \mathrm{H}),{ }^{13} \mathrm{C}$ NMR (175 MHz, $\left.\mathrm{CDCl}_{3}\right), \delta: 167.37,158,156.46,148,141,134.47,131.79,128.21,127.07$, $123.81,119.56$.

Diphenylidene-4,4'-dicarboxy-naphthalene-1,5-diamine, (CA-2). Yield 90\%, m.p. $=251{ }^{\circ} \mathrm{C}$, FTIR $\left(\mathrm{KBr}, \mathrm{cm}^{-1}\right)$ : 3500-2820 (m, br, $\left.\mathrm{COOH}\right), 1701(\mathrm{C}=\mathrm{O}), 1626(\mathrm{CH}=\mathrm{N}), 1580(\mathrm{C}=\mathrm{C}) .{ }^{1} \mathrm{HNMR}$ $\left(500 \mathrm{MHz}, \mathrm{DMSO}-d_{6}\right), \delta: 10.49(\mathrm{~s}, 2 \mathrm{H}, \mathrm{OH}), 8.24(\mathrm{~s}, 2 \mathrm{H}, \mathrm{CH}=\mathrm{N}), 8.31(\mathrm{~d}, J=8.6 \mathrm{~Hz}, 4 \mathrm{H})$, $7.87(\mathrm{~d}, J=8.4 \mathrm{~Hz}, 4 \mathrm{H}), 7.48-7.35(\mathrm{~m}, 6 \mathrm{H})$.

4-(pyridin-4-ylimino)methyl)thieno [3,2-b]thiophen-5-yl)methylene)pyridin-4-amine, (Py-1). Yield $85 \%$, m.p. $>300{ }^{\circ} \mathrm{C}$, FTIR $\left(\mathrm{KBr}, \mathrm{cm}^{-1}\right)$ : 3010, $1618(\mathrm{C}=\mathrm{N})$. $1 \mathrm{H}$ NMR $\left(500 \mathrm{MHz}, \mathrm{CDCl}_{3}\right)$ : $\delta 8.29(\mathrm{~s}, 2 \mathrm{H}, \mathrm{CH}=\mathrm{N}), 7.78(\mathrm{~d}, J=8.4 \mathrm{~Hz}, 4 \mathrm{H}, \mathrm{Py}), 7.14(\mathrm{~d}, J=8.4 \mathrm{~Hz}, 4 \mathrm{H}, \mathrm{Py}), 6.98(\mathrm{~s}$, $2 \mathrm{H}$, thioph).

4-((pyridin-4-yl)methyleneamino)phenoxy)-N-((pyridin-4-yl)methylene)benzenamine, (Py-2). Yield $82 \%$, m.p. $=285^{\circ} \mathrm{C}$ (decomp.), FTIR $\left(\mathrm{KBr}, \mathrm{cm}^{-1}\right): 1626(\mathrm{CH}=\mathrm{N}), 1580(\mathrm{C}=\mathrm{C}),{ }^{1} \mathrm{H}$ NMR $\left(500 \mathrm{MHz}, \mathrm{CDCl}_{3}\right)$ 8: $9.01(\mathrm{~s}, 2 \mathrm{H}, \mathrm{CH}=\mathrm{N}), 8.71(\mathrm{~d}, J=8.5 \mathrm{~Hz}, 4 \mathrm{H}), 8.45(\mathrm{~d}, J=8.5 \mathrm{~Hz}, 4 \mathrm{H})$, $8.39-8.56(\mathrm{~m}, 4 \mathrm{H}), 7.50-6.86(\mathrm{~m}, 4 \mathrm{H})$.

4-(pyridin-4-ylimino)methyl)thiophen-2-yl)methylene)pyridin-4-amine, (Py-3). Yield $88 \%, \mathrm{~m} . \mathrm{p} .=280{ }^{\circ} \mathrm{C}$, FTIR $\left(\mathrm{KBr}, \mathrm{cm}^{-1}\right): 3018,1636(\mathrm{C}=\mathrm{N}) .1 \mathrm{H}$ NMR $\left(500 \mathrm{MHz}, \mathrm{CDCl}_{3}\right): \delta 8.60(\mathrm{~s}, 2 \mathrm{H}, \mathrm{CH}=\mathrm{N})$, $8.04(\mathrm{~d}, J=8.5 \mathrm{~Hz}, 4 \mathrm{H}, \mathrm{Py}), 7.49$ (s, 2H, thioph), 7.35 (d, J = 8.5 Hz, 4H, Py). ${ }^{13} \mathrm{C}$ NMR, $\delta 156$, $146,144,132,131,129$.

\subsubsection{Optical Spectroscopy}

The UV/Vis absorption spectra of solution-based free dyes (in N,N-dimethylformamide) were determined using a Thermo Scientific Evolution 201/220 UV-Visible Spectrophotometers (Mettler-Toledo India Private Limited, Mumbai, India). The uncertainty in the UV/vis measurement is $2 \mathrm{~nm}$.

\subsection{Computational Methodology}

2.2.1. Ground State Studies of Isolated Dyes

The ground state geometries of all the new synthesized dyes as well as the reference dye (VG20- $\mathrm{C}_{2}$ ) were optimized using DFT method with the M06-2X/6-311g $(\mathrm{d}, \mathrm{p})$ level of theory $[24,25]$. This method is widely accepted and reliable in probing the non-covalent interactions (NCIs) [26] which will be assessed for the electronic structure of the studied dimer. The effect of $\mathrm{N}, \mathrm{N}$-dimethylformamide (DMF), the solvent that was used in measuring UV-Vis spectra of new synthesized dyes, was accounted for using the self-consistent reaction field (SCRF) based on the conductor-like polarizable continuum model (C-PCM). Frequency calculations at the same level of theory were subsequently performed in order to verify that the optimized geometrical structures were converged to true stationary points not saddle points. All geometries were optimized with tight convergence criteria 
corresponding to Max force $=1.5 \times 10^{-5}$ and RMS force $=1.0 \times 10^{-5}$ Hartree Bohr $^{-1}$ as well as Max displacement $=6.0 \times 10^{-5}$ and RMS displacement $=4.0 \times 10^{-5} \mathrm{Bohr}$.

\subsubsection{Excited State Studies of Isolated Dyes}

Based on the optimized molecular structures, the optical properties were simulated using time-dependent DFT (TD-DFT) [27] excited-state calculations. Benchmark calculations were carried out on all synthetized dyes with different exchange-correlation XC functionals $(\mathrm{XCFs})$. The theoretical results were compared with experimental data derived from UV-visible absorption spectra. M11 functional demonstrated better performance with the lowest MAE values, therefore, M11/6-311g(d,p)/C-PCM(DMF) level of theory was chosen to simulate the electronic excitations for all the studied compounds. Furthermore, the excited state geometries were optimized and the UV-Vis emission spectra of new dyes were calculated, at the same level of theory, in order to explore the possibility of excitation energy transfer between cosensitizers. All calculations were performed using Gaussian 09 (revision D.01) quantum chemistry software [28]. The electron excitation analysis module, as implemented in Multiwfn 3.8 code [29], was then employed for hole-electron analysis [30] upon photoexcitation besides analyzing quantitatively the intramolecular charge transfer (CT) using interfragment charge transfer (IFCT) analysis.

\subsubsection{Ground State Studies of Adsorbed Dyes}

The efficiency of electron injection, from the new dyes into the $C B$ of $\mathrm{TiO}_{2}$, was assessed by investigating the interfacial electronic structure of adsorbed isolated dyes on the surface of $\mathrm{TiO}_{2}$. Hence, a cluster model of $\left(\mathrm{TiO}_{2}\right)_{38}$ was constructed by appropriately cutting an anatase slab, exposing the majority (101) surface, which was comprised of two layers with $19 \mathrm{Ti}$ atoms on each side. Following the work by Persson et al. [31], appropriate cleaving was achievable by systematic stripping off stoichiometric units $\left(\mathrm{TiO}_{2}\right)_{\mathrm{n}}$ from supercell, such that the constructed cluster is stoichiometric, lacking permanent dipole moment, and with high coordination of every constituent atom. The ground state geometries of the bare $\left(\mathrm{TiO}_{2}\right)_{38}$ cluster and of the corresponding dye-adsorbed structures were optimized by the Amsterdam density functional program (ADF) program [32], as integrated into AMS2020.103 software package [33] based on the zero-order regular approximation (ZORA) [34] two-component relativistic Hamiltonian. The ZORA Hamiltonian is the zero-order regular approximation to the Dirac Hamiltonian including a scalar relativistic (SR) and a spin-orbit coupling (SOC) part. The generalized gradient approximation of Perdew-Burke-Ernzerhof (PBE) [35] functional was used in conjunction with Slater-type orbital basis sets [36] TZP/DZP for Ti/H, C, N, O, and S atoms. The considered adsorption mode for carboxyl anchor-based dyes is the bridged homogeneous bidentate mode with both carboxylic oxygens of anchoring group of dye interact with penta-coordinated (5c) Ti sites on two successive rows with proton transferred to nearby surface oxygen (2c) atom. For Pyridyl anchor-based dyes, the monodentate adsorption mode with penta-coordinated (5c) Ti site was adopted.

\subsubsection{Electronic Structure of Dimer}

For the suggested promising cosensitizer, optimized geometries of monomers were used to construct 50 initial cluster configurations using Genmer tool in Molclus code [37]. Molclus was then employed to invoke MOPAC 2016 software [38] for sequential batch optimization of the 50 configurations using the PM7 [39] (Parametrization method 7) semiempirical quantum mechanics method. Subsequently, Isostat tool in Molclus code was used for sorting the 50 cluster configurations by energy and deleting duplicated structures. Finally, fine optimization of the most suitable lowest energy dimer configuration was performed with M06-2X-D3/6-311G $(\mathrm{d}, \mathrm{p})$ level of theory including the D3 dispersioncorrection [40] using Gaussian 09 software. The chemical compatibility and stability of the electronic structures of cosensitizers was further investigated by calculating the interaction energies for the heterodimer and performing simple energy decomposition analysis (EDA). 
The nature of intermolecular interactions between proposed cosensitizers was then studied by none-covalent interaction (NCI) method [41] as supported by Multiwfn 3.8 code along with VMD visualization code [42].

\subsubsection{XC-Functionals Assessment}

Excitation energies are related to the response of the system to an electromagnetic field; therefore, they depend on how well the virtual orbitals are described. Since complexities of all quantum-mechanical contributions of the many-body problem are cast into the exchange-correlation $(X C)$ functional $E_{X C}[\rho]$, then predictive power of DFT calculations depends solely on the validity of the chosen approximation to the XCF [43]. Accordingly, UV-Vis absorption spectra for all studied compounds were simulated using 11 different XCFs: the hybrid generalized-gradient approximation (GGA) functional B3LYP [44] with 20\% HFX (Hartree-Fock exchange); the range-separated hybrid (RSH) GGA functional CAM-B3LYP [45] (19\% HFX at short range and 65\% HFX at long range); the RSH meta-GGA functional M11 [46] (42.8\% HFX at short range and 100\% HFX at long range); the RSH with dispersion effects, wB97X-D [47] (22\% HFX at short range and 100\% HFX at long range); the RSH-GGA functional HSE06 [48,49] $(25 \%$ HFX at short range and 0\% HFX at long range); the RSH meta-nonseparable gradient approximation (NGA) functional MN12SX [50] (25\% HFX at short range and 0\% HFX at long range); the RSH-NGA functional N12-SX [50] (25\% HFX at short range and 0\% HFX at long range); the RSH-GGA functional HISS [51,52] (0\% HFX at short range, $60 \%$ HFX at middle range and $0 \%$ HFX at long range); and the meta-GGA hybrid functionals: M06-2X [24] (54\% HFX), TPSSh [53] (10\% HFX) and $\tau$-HCTH hyb [54] (15\% HFX).

The meta-GGA hybrid functionals were chosen as an increasing order of the percent of Hartree-Fock exchange (HFX\%) added to the functional, whereas the RSH functionals were chosen to be belonged to three different categories. Namely the screened-exchange functionals (HSE06, N12-SX and MN12-SX) for which the HFX\% decreases monotonically from a finite value $(25 \%)$ at short interelectronic separations (short range) to zero at long interelectronic separations (long range); the middle-range functional (HISS) for which $\mathrm{HFX} \%$ increases from zero at short range to a finite value $(60 \%)$ at medium interelectronic separations and then decreases to zero at long range; the long-range-corrected functionals (M11 and $\omega$ B97X-D) for which HFX\% increases monotonically from a finite value at short range to $100 \%$ at long range; and the CAM-B3LYP functional, for which $X$ increases monotonically with increase in interelectronic separation, but not all the way up to $100 \%$ at long range. The mean signed deviation was calculated as: $M S D=\frac{1}{n} \sum_{i=0}^{n}\left(\lambda_{\text {calc }}-\lambda_{\text {exp }}\right)$, for the absorption maximum wavelength $\left(\lambda_{\max }\right)$ obtained using the eleven XCFs. While the mean absolute error $(M A E)$ was calculated as: $M A E=\frac{1}{n} \sum_{i=1}^{n}\left|\lambda_{\text {calc }}-\lambda_{\text {exp }}\right|$. As shown in Figure 1, M06-2X as well as the long-range corrected functionals (M11, CAM-B3LYP and $\omega B 97 X-D)$ outperform other functionals in reproducing the excitation energies of pyridine anchor-based set (Py1-Py3) and providing the least MSD. Among these functionals, the long-range-corrected RSH meta-GGA functional M11 is the best performing XCF with MSD of ca. +26, 14, $24 \mathrm{~nm}$ for Py1, Py2 and Py3, respectively. Whereas, for the $-\mathrm{COOH}$ anchor-based set (CA1 and CA2), the screened-exchange meta-NGA functional MN12-SX and the middle-range functional (HISS) are the most accurate. This could be attributed to the different types of excitations and different degree of spatial overlap between frontier molecular orbitals. In systems with large rearrangement of charge upon photoexcitation, the asymptotic behavior of M11, M06-2X, CAM-B3LYP and $\omega$ B97X-D functionals could lead to a better description of the excitations. In terms of $M A E$, the values were found within a range of 26-78 nm, with following trend: M11 < M06-2X < $\omega$ B97X-D < CAMB3LYP $<$ HISS < MN12-SX < HSE06 < N12-SX < B3LYP < $\tau$-HCTH hyb $<$ TPSSh. For the present two sets of molecules, the most reliable XCF turns out to be M11, with a MAE of $26 \mathrm{~nm}$. 


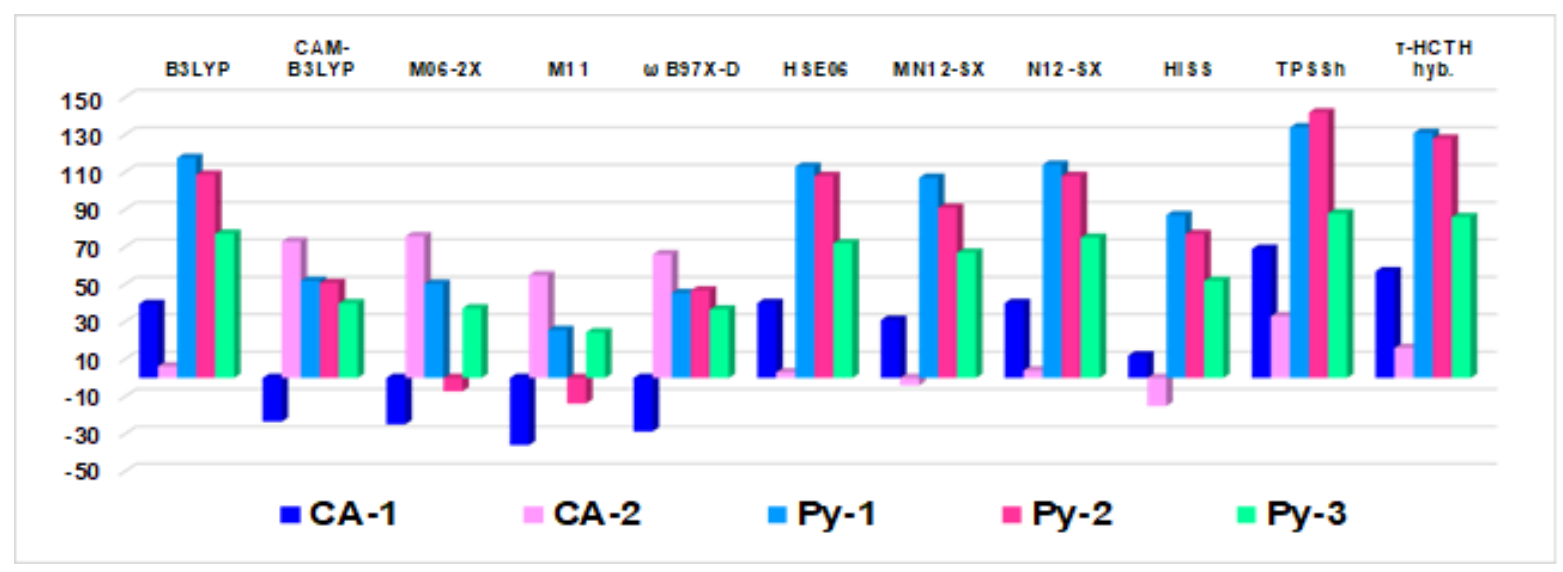

Figure 1. Mean signed deviation (nm) of calculated $\lambda_{\max }$ to experimental $\lambda_{\max }$.

\subsubsection{Characterization of Electrochemical Properties for Isolated dyes}

One of the three factors that determines the overall power conversion efficiency (PCE) of the DSC device is the short-circuit photocurrent density (JSC), which can be calculated using the following equation [55]:

$$
\mathrm{J}_{\mathrm{SC}}=\int \operatorname{LHE}(\lambda) \Phi_{\text {inject }} \eta_{\text {collect }} \mathrm{d} \lambda
$$

LHE is light-harvesting efficiency at wavelength $\lambda$, $\Phi_{\text {inject }}$ is the quantum yield for the electron injection efficiency, and $\eta_{\text {collect }}$ is the charge collection efficiency which is controllable by the architecture of DSCs only. In contrast, LHE and $\Phi_{\text {inject }}$ strongly depend on the structural and quantum phenomenon of the dye. The LHE is related to the oscillator strength $f$ of the dye at the maximum absorption wavelength $\left(\lambda_{\max }\right)$, and is expressed as [56]

$$
\operatorname{LHE}(\lambda)=1-10^{-\mathrm{f}}
$$

The electron injection efficiency $\Phi_{\text {inject }}$ from the photoinduced excited states of organic dyes into the conduction band $(C B)$ of the semiconductor can be related to the free energy change for the electron injection, where $\Phi_{\text {inject }} \propto \mathrm{f}\left(-\Delta G_{i n j}\right)$. The electron injection driving force $\left(\Delta G_{i n j}\right)$ can be defined through the following equation [55,57]:

$$
\Delta G_{i n j}=E_{C B}^{\mathrm{TiO}_{2}}-E_{o x}^{*}=E_{C B}^{\mathrm{TiO}_{2}}-\left(E_{o x}+E_{0-0}\right)
$$

where $E_{o x}^{*}$ and $E_{o x}$ are the oxidational potential of the dye in excited state and ground state, respectively. $E_{C B}^{\mathrm{TiO}_{2}}$ is the reduction potential of the $C B$ of $\mathrm{TiO}_{2}$, in which the experimental value $-4.00 \mathrm{eV}$ [58] (vs. vacuum) was used and $E_{0-0}$ is the electronic vertical transition energy at $\lambda_{\max }$. The driving force for efficiency of dye regeneration $\left(\Delta G_{r e g}\right)$ is calculated via the following equation $[59,60]$ :

$$
\Delta G_{r e g}=E_{\left(I^{-} / I_{3}^{-}\right)}-E_{o x}
$$

In which $E_{\left(\mathrm{I}^{-} / \mathrm{I}_{3}^{-}\right)}$is the oxidation potential of the electrolyte $(-4.8 \mathrm{eV})$ [61]. Furthermore, the competing loss pathway (dark current), namely the recombination reaction of the injected electrons in $C B$ of $\mathrm{TiO}_{2}$ with $\mathrm{I}_{3}{ }^{-}$ions in the electrolyte solution can be assessed using the free energies driving force of recombination reaction according to the following equation $[59,62]$ :

$$
\Delta G_{r e c}=E_{C B}^{\mathrm{TiO}_{2}}-E_{o x}
$$

Accordingly, Equations (2)-(5) are to be employed in this study for estimating the photovoltaic (PV) performance of DSCs employing the new synthesized dyes. 


\section{Results and Discussion}

\subsection{Ground State Geometrical Structures of Isolated Sensitizer}

Usually, the conjugation degree of the dye photosensitizer has a substantial impact on the absorption of light and the consequential electronic transitions. Structural attributes, such as the critical twist angles between dye's fragments, directly disturb the degree of conjugation. The five synthesized dyes are represented in Figure 2 with displaying the positions of critical dihedra angles, where their calculated values are listed in Table 1. The dyes are grouped into two sets of molecules according to the type of anchoring group; namely CA set with the $-\mathrm{COOH}$ anchor and Py set with pyridine ring as an anchor. The optimized geometries of the free dyes are displayed in Figure S1 (see the Supplementary Materials).

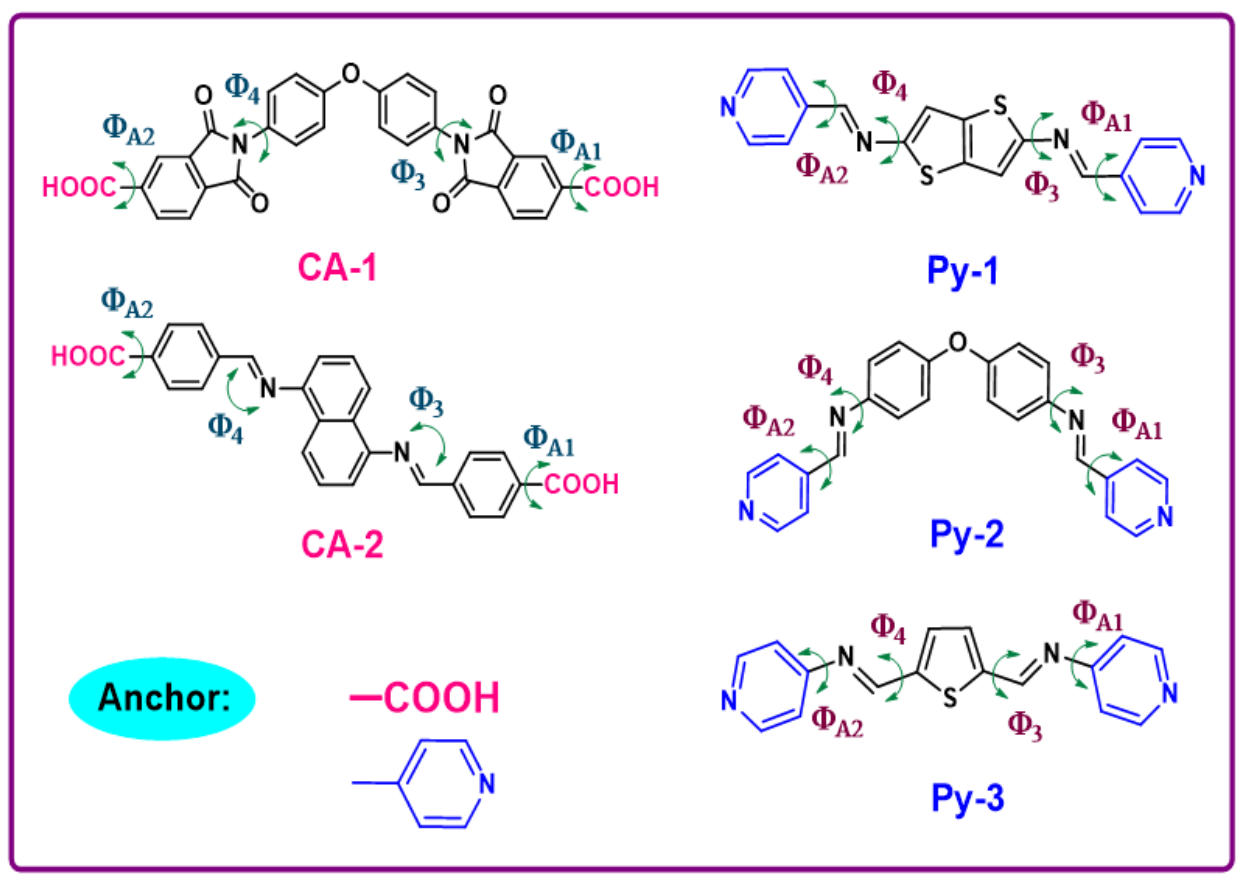

Figure 2. Molecular structures of the new sensitizers with critical dihedral angles positions.

Table 1. Calculated Critical Dihedral Angles of New Sensitizers at Ground State (S0) Geometry.

\begin{tabular}{cccccc}
\hline & CA-1 & CA-2 & Py-1 & Py-2 & Py-3 \\
\hline$\Phi_{\text {A1 }}$ & 24 & 23 & 0.09 & 2 & 45 \\
$\Phi_{\mathrm{A} 2}$ & 24 & 23 & 0.02 & 2 & 45 \\
$\Phi_{3}$ & 50 & 46 & 0.2 & 37 & 1 \\
$\Phi_{4}$ & 49 & 46 & 29 & 40 & 1 \\
\hline
\end{tabular}

Comparing the dyes with $-\mathrm{COOH}$ anchor, all geometries deviate from the planarity by ca. $29-50^{\circ}$ due to the steric repulsion between rings, where the diimide CA-1 dye obtained a bent shaped geometry as the rings in diphenyl ether tend to be on planes perpendicular to each other. Considering the dyes with pyridine anchor, Py-1 dye has significantly enhanced the planarity and can be considered the most planar structure among the studied dyes. Similar to CA-1 dye, Py-2 dye showed a bent shaped geometry with the two rings of diphenyl ether are in planes at right angles to each other.

Comparing the significant increment of $\Phi_{\mathrm{A} 1}$ and $\Phi_{\mathrm{A} 2}$ twist angles of Py-3 (ca. $45^{\circ}$ ) than Py- $1\left(\right.$ ca. $2^{\circ}$ ), where they have same pyridine anchor but with different attachment points to imine $(-\mathrm{CH}=\mathrm{N}-)$ linkage, namely imine carbon and imine nitrogen of Py-1 and Py-3, respectively. It is obvious that improved conjugation of the $\pi$-cloud of dithiophene moiety with the lone pair of imine $\mathrm{N}$ in Py-1 dye enforces the planarity of its conjugated system. 
This is reflected in the bond lengths of thiophene- $\mathrm{C}-\mathrm{N}$ (imine) and thiophene- $\mathrm{C}-\mathrm{C}$ (imine) of Py- 1 and Py- 3 dyes, which were found to be $1.37 \AA$ and $1.45 \AA$, respectively.

According to the basic principle of DSCs, after excitation of the dye by incident light, an oxidized state of the dye is formed by electron injection into the conduction band $(C B)$ of the anode (here $\mathrm{TiO}_{2}$ ). Since maintaining the planarity between the anchoring group and the molecular plane is critically required for the ease of charge flow and electron injection into the $C B$ of $\mathrm{TiO}_{2}$, then we could argue that Py-1 and Py-2 dyes will show enhanced electron injection efficiency, according to their lowest values of $\Phi_{\mathrm{A} 1}$ and $\Phi_{\mathrm{A} 2}$ dihedral angles.

\subsection{Frontier Molecular Orbitals Analysis}

For efficient operation of DSC, the lowest unoccupied molecular orbital (LUMO) of the dye should be higher than the $C B(-4.00 \mathrm{eV})$ of $\mathrm{TiO}_{2}$, with at least $0.2 \mathrm{eV}$ [63], to guarantee efficient electron injection. Similarly, the highest occupied molecular orbital (HOMO) of the dye should lie below the energy level $(-4.8 \mathrm{eV})$ of the iodine/triiodide $\left(\mathrm{I}^{-} / \mathrm{I}_{3}^{-}\right)$redox electrolyte for effective regeneration of the oxidized dyes. The energy levels involving $\mathrm{E}_{\mathrm{HOMO}}$ and $\mathrm{E}_{\mathrm{LUMO}}$ and their energy gaps of all new dye molecules are shown in Figure 3, together with the energies of $\mathrm{I}^{-} / \mathrm{I}_{3}^{-}$redox potential and $C B$ of $\mathrm{TiO}_{2}$ for a direct comparison. It can be seen that the calculated LUMO energy levels of all dyes range from -2.02 to $-1.37 \mathrm{eV}$, which are about 1.98 to $2.63 \mathrm{eV}$ higher than the $C B$ of $\mathrm{TiO}_{2}$. Accordingly, thermodynamically favored electron injection reactions can be predicted for both CA and Py dyes. Additionally, the HOMO energy levels ranging from -7.85 to $-7.01 \mathrm{eV}$ are significantly lower than the electrode potential of the redox couple $(-4.8 \mathrm{eV})$, implying that thermodynamically favored regeneration reactions are expected for all dyes. Evidently, $\mathrm{E}_{\mathrm{HOMO}}$ and $\mathrm{E}_{\mathrm{LUMO}}$ of all studied dyes meet the basic energetic requirements for operating DSCs; however, the HOMO level of Py-3 shifts toward more negative value $(-7.85 \mathrm{eV})$ suggesting easier regeneration of the oxidized dye with greater driving force, when compared to other dyes.

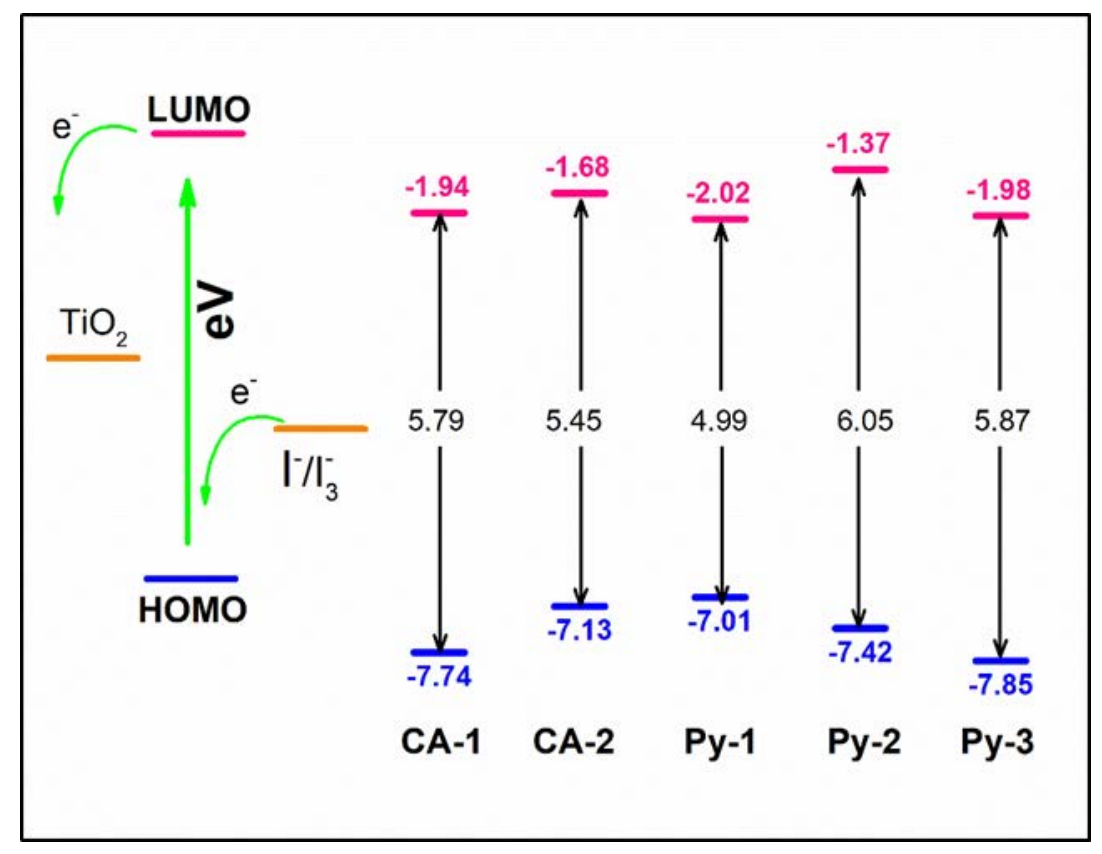

Figure 3. Energy level diagram of the $\mathrm{HOMO}$ and $\mathrm{LUMO}$ for all dyes, $\mathrm{TiO}_{2}$, and the electrolyte.

Furthermore, Figure 3 vividly shows that Py- 1 dye possesses the smallest HOMOLUMO energy gap (Eg) of $4.99 \mathrm{eV}$. This can be attributed to the inclusion of fused thienothiophene heterocycle, which increases the conjugation length thus, causes lower energy gaps and eases the photoexcitation of dye molecules. This result is consistent with the 
previously detected enhanced planarity of Py-1 dye. Since strong acceptor decreases the $\mathrm{E}_{\mathrm{LUMO}}$, then one can assume that pyridine rings of Py- 1 and Py-3 would have greater accepting power according to their lowest $(-2.02$ and $-1.98 \mathrm{eV})$ values of $E_{\mathrm{LUMO}}$, which is beneficial for operating DSC.

The contour plots of the FMOs for the six dyes are depicted in Figure 4. Considering CA-1 and Py-2 dyes, the HOMO electron density is mostly located on the diphenyl ether unit, whereas the LUMO is predominantly spread to the acceptor units, which satisfies the requirements of the molecular orbital for charge separation. Distinct hole-electron separation could not be estimated for CA-2 and Py-3 dyes as the electron densities of their FMOs are nearly distributed throughout the entire molecular backbones. Concerning Py-1 dye, its structural attributes and pattern of FMOs distributions can suggest promising injection of excited charge into $\mathrm{CB}$ of $\mathrm{TiO}_{2}$, particularly for increased localization of LUMO on the pyridine anchor as conjugated with the imine group. The same conclusion was previously drawn for some squarine dyes with planar structure and great $\pi$-electron density conjugation along molecular backbone [64].

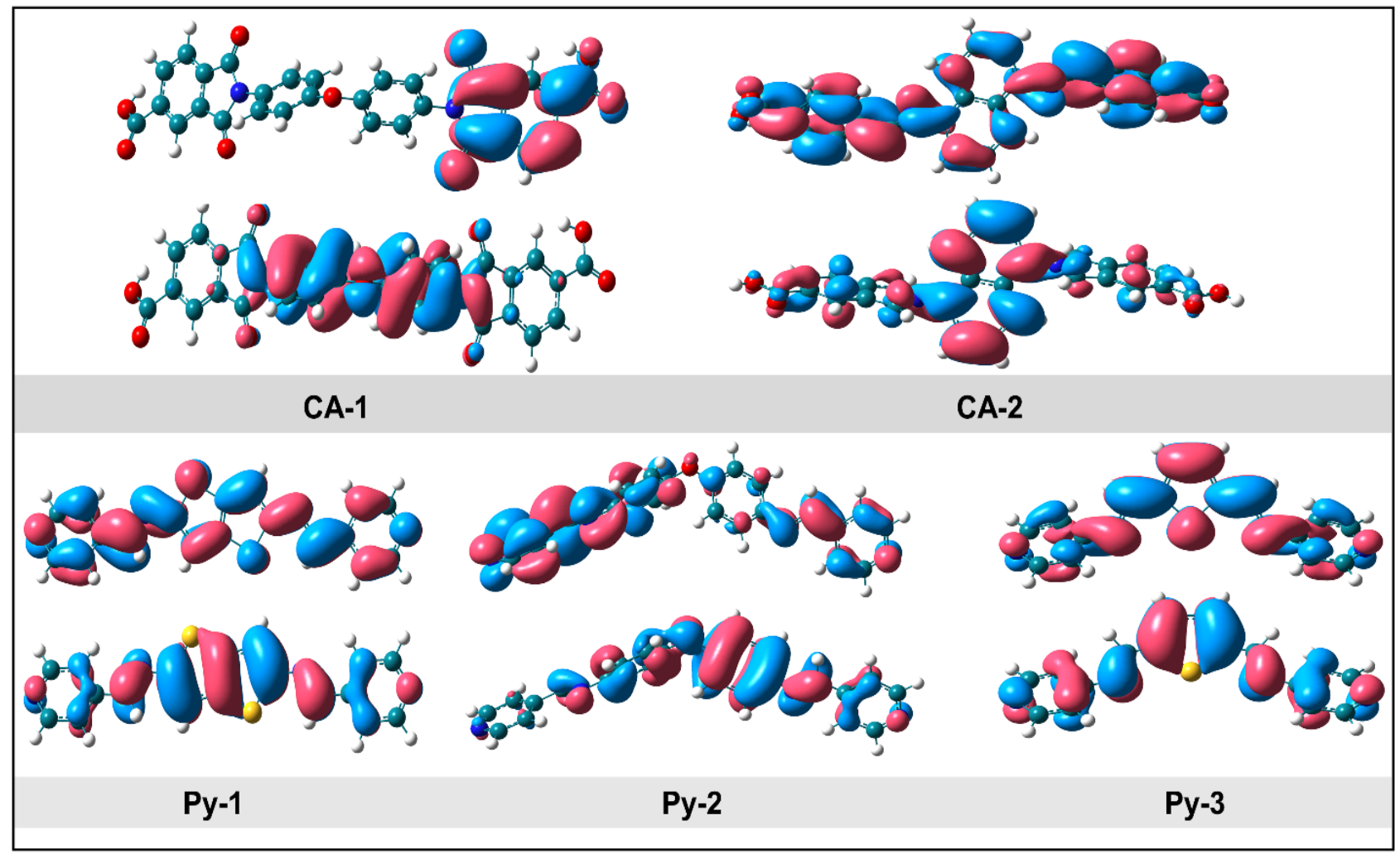

Figure 4. Contour plots of the HOMO and LUMO of isolated dyes. In all the cases the isovalue is set to 0.02. HOMO level is depicted below and LUMO level is depicted above for each dye design.

\subsection{Photoabsorption Spectra of Free Dyes}

The light absorption behavior of the cosensitizer is a crucial factor for evaluating its photophysical properties and determining its ability to achieve complementarity of absorption spectrum. Figure 5 depicts the experimental UV-Vis spectra of the synthesized UV-dyes, measured in DMF solvent. Table 1 lists the optical data obtained from TD-DFT calculations along with the experimental measurements of $\lambda_{\max }$. The dominant character of the transitions was assigned according to the relocations of the FMOs (Figures 4 and S2), in which each excited state is characterized by either intramolecular charge transfer (ICT), $\pi-\pi^{*}$ local excitation (LE) or hybridized local excitation-CT (HLCT) state. HLCT state occurs when a localized excitation is present close to the CT excitation [65]. 


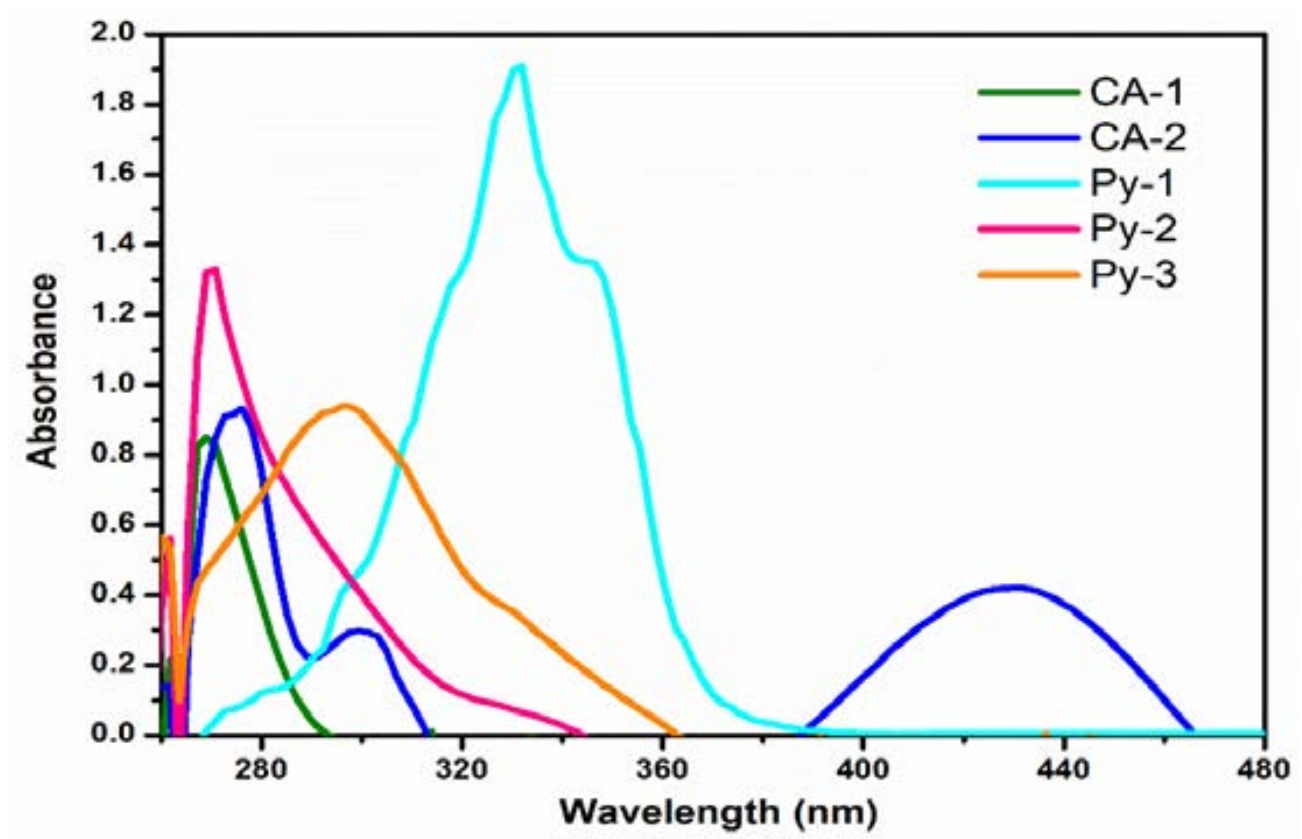

Figure 5. Experimental UV-Vis spectra of the synthesized dyes measured in DMF solvent.

The experimental UV-Vis spectra (Figure 5) show that all dyes exhibit an absorption band covering the mid-UV/near-UV region $(269-330 \mathrm{~nm})$ of solar spectrum. The relative bathochromic shift of Py-1 dye is signifying the previously calculated lower energy gab between the frontier molecular orbitals due to boosted planarity and conjugation length. Additionally, a hyperchromic shift is observed for Py-1 dye which is attributable to the incorporation of fused thienothiophene heterocycle. Judicious choice of fused conjugation unit of Py-1 dye is expected to enhance the light-harvesting capability and ultimately the higher PCE. The calculated electronic absorptions (Table 2) agree with the experimental observations in reproducing the relative red-shifted $\lambda_{\max }$ of Py- 1 dye.

Table 2. Experimental and calculated TD-DFT Excitation Energies (eV, nm), Oscillator Strengths (f), Compositions in Terms of Molecular Orbital Contributions, and Dominant Character of the Transitions.

\begin{tabular}{cccccccc}
\hline Dye & State & $\operatorname{Exp} \lambda_{\max }$ & $\lambda_{\max }$ & $\mathbf{E ~ ( e V )}$ & $\mathbf{f}$ & Major Contribution & Dominant Transition \\
\hline CA-1 & S0 $\rightarrow$ S12 & 270 & 234 & 5.30 & 1.74 & $\mathrm{H} \rightarrow \mathrm{L}+5(45 \%) ; \mathrm{H} \rightarrow \mathrm{L}+2(21 \%)$ & $\pi-\pi^{*}(\mathrm{LE})$ \\
$\mathrm{CA}-2$ & $\mathrm{~S} 0 \rightarrow \mathrm{S} 1$ & 276 & 332 & 3.72 & 0.85 & $\mathrm{H} \rightarrow \mathrm{L}(64 \%) ; \mathrm{H}-1 \rightarrow \mathrm{L}+1(11 \%)$ & $\pi-\pi^{*}(\mathrm{LE})+\mathrm{ICT}(\mathrm{HLCT})$ \\
Py-1 & $\mathrm{S} 0 \rightarrow \mathrm{S} 1$ & 332 & 370 & 3.35 & 1.53 & $\mathrm{H} \rightarrow \mathrm{L}(86 \%) ; \mathrm{H}-2 \rightarrow \mathrm{L}+1(5 \%)$ & $\pi-\pi^{*}(\mathrm{LE})+\mathrm{ICT}(\mathrm{HLCT})$ \\
Py-2 & $\mathrm{S} 0 \rightarrow \mathrm{S} 5$ & 269 & 255 & 4.86 & 1.17 & $\mathrm{H}-8 \rightarrow \mathrm{L}+1(23 \%) ; \mathrm{H} \rightarrow \mathrm{L}(12 \%)$ & $\pi-\pi^{*}(\mathrm{LE})+\mathrm{ICT}(\mathrm{HLCT})$ \\
Py-3 & S0 $\rightarrow \mathrm{S} 1$ & 298 & 320 & 3.87 & 1.08 & $\mathrm{H} \rightarrow \mathrm{L}(87 \%) ; \mathrm{H}-1 \rightarrow \mathrm{L}+1(6 \%)$ & $\pi-\pi^{*}(\mathrm{LE})$ \\
\hline
\end{tabular}

For CA-2, Py- 1 and Py-3 dyes, the maximum light absorption at $\lambda_{\max }$ corresponds to first electronic transition $\mathrm{S} 0 \rightarrow \mathrm{S} 1$, with $\mathrm{HOMO} \rightarrow \mathrm{LUMO}$ being the major $(64-87 \%)$ contributing molecular orbitals. Since the spatial distributions of HOMO and LUMO for these dyes reflects electron delocalization over the entire molecule, with greater localization of LUMO on the anchoring groups of Py- 1 and CA-2. Thus, transitions of Py-1 and CA-2 are characterized by hybridized ICT-local $\pi-\pi^{*}$ excitation (HLCT), whereas for Py-3, the local $\pi \rightarrow \pi^{*}$ excitation is the primary transmission mode.

The main absorption peak of CA-1 dye with $\lambda_{\max }$ at $270 \mathrm{~nm}$ is mainly made up of S12 state. This predominantly corresponds to $\mathrm{HOMO} \rightarrow \mathrm{LUMO}+5(45 \%)$ and $\mathrm{HOMO} \rightarrow \mathrm{LUMO}+2(21 \%)$, where HOMO and LUMO +5 orbitals are distributed over the same diphenyl ether unit while LUMO + 2 is localized on isoindoline-1,3-dione. Consequently, $\mathrm{S} 0 \rightarrow \mathrm{S} 12$ electronic transition can be assigned as HLCT. Similarly, S5 excited state of Py-2, involves local electron excitation in the imine and pyridine units $(\mathrm{HOMO}-8 \rightarrow \mathrm{LUMO}+1)$ addition to 
intramolecular $C T$ from diphenyl ether to imine and pyridine (HOMO $\rightarrow$ LUMO) i.e., HLCT transition. The larger values of oscillator strength $(\mathrm{f})$ is regarded to larger values of transition electric-dipole moment, which means that $\mathrm{S} 0 \rightarrow \mathrm{S} 1$ transition of Py-1 is a strongly electric-dipole allowed transition. Overall, optical properties of all new UV-absorbing dyes suggest the obtainability of complementarity of absorption spectrum when combined with the NIR-absorbing VG20 reference dye, particularly, Py-1 dye with boosted light-harvesting capability.

\subsection{Emission Characteristics}

Assessing the nature of the fluorescent state of photosensitizing dyes is one of the foremost tasks, since long lifetime of stable fluorescent state endows a substantial role in the electron mobilization process in DSCs [66]. Therefore, the linear response (LR) TD-M11/CPCM calculations have been carried out to reveal the kinetics of decays of the excited states. The radiative lifetime was then calculated through the Einstein transition model [67] $\tau_{f l u}=c^{3} /\left(2 \times\left(E_{f l u}\right)^{2} \times \mathrm{f}\right)$, in which $c$ stands for speed of light in au, $E_{f l u}$ is the fluorescence transition energy in $\mathrm{cm}^{-1}$ and $\mathrm{f}$ is the oscillator strength for the $\mathrm{S} 0 \leftarrow \mathrm{S} 1$ transition. Table 3 lists the fluorescence energies $E_{f l u}(\mathrm{eV})$, fluorescence wavelengths $\lambda_{\mathrm{em}}(\mathrm{nm})$, oscillator strengths (f) and radiative lifetimes of the first excited states (S1).

Table 3. Calculated TD-M11 fluorescence energies $E_{f l u}$, fluorescence wavelengths $\lambda_{\mathrm{emi}}$, oscillator strengths (f) and radiative lifetimes.

\begin{tabular}{ccccc}
\hline Dye & $\boldsymbol{E}_{\boldsymbol{f l u}}(\mathrm{eV})$ & $\lambda_{\max }(\mathrm{nm})$ & $\mathbf{f}$ & $\boldsymbol{\tau}_{\boldsymbol{f l u}}(\mathrm{ns})$ \\
\hline CA-1 & 3.732 & 332 & 0.0004 & 3.548 \\
CA-2 & 3.428 & 362 & 0.9238 & 0.002 \\
Py-1 & 2.988 & 415 & 1.4261 & 0.002 \\
Py-2 & 4.013 & 309 & 0.3477 & 0.004 \\
Py-3 & 3.590 & 345 & 0.0416 & 0.037 \\
\hline
\end{tabular}

Figure 6 displays the computed emission spectra of the synthesized dyes along with a comparison with the corresponding experimental absorption maxima and calculated Stokes shift (red shift) of the fluorescent state. Notably, emission spectra of the studied dyes showed emission peaks in the range of 309-415 $\mathrm{nm}$. The optimized geometries of emission states are shown in Figure S3 (see the Supporting Information). The optimized structures show that $\Phi_{3}$ and dihedral angle of CA-1 has decreased by ca. $25^{\circ}$ in comparison to the ground-state. Similarly, an enhanced planarity has been obtained for Py-3 dye with ca. $18^{\circ}$ lower $\Phi_{\mathrm{A} 1}$ and $\Phi_{\mathrm{A} 2}$ relative to the ground-state geometry.

A perpendicularly twisted terminal benzylidene carboxylic acid group and pyridine group to the molecular plane, has been found in CA-2 and Py-1, respectively. Accordingly, emission peak of their fluorescence spectrum could be attributed to a twisted, relaxed excited state. The calculated larger values of the Stokes shift of CA-1, CA-2 and Py1 dyes lying in the range of $63-88 \mathrm{~nm}$ are indicative of their structural flexibility upon photoexcitation. For CA-1 dye, despite showing the longest lifetime (3.5 ns) for fluorescence process, its negligible value of oscillator strength (ca. 0.0004) indicates that no emission exists. On the other hand, the results revealed that Py- 1 and CA-2 dyes showed the largest emission peaks and Stokes shifts with the lowest radiative lifetime.

Since the emitted photons can be trivially reabsorbed if the absorption and fluorescence spectra of the cosensitizers overlap [68], the possibility of excitation energy transfer from any of the new synthesized UV-dyes to the proposed VG20 cosensitizer is not expected for the reason that there is no overlapping between absorption spectrum of VG20 $(826 \mathrm{~nm})$ and fluorescence spectra of the UV dyes (309-415 nm). 


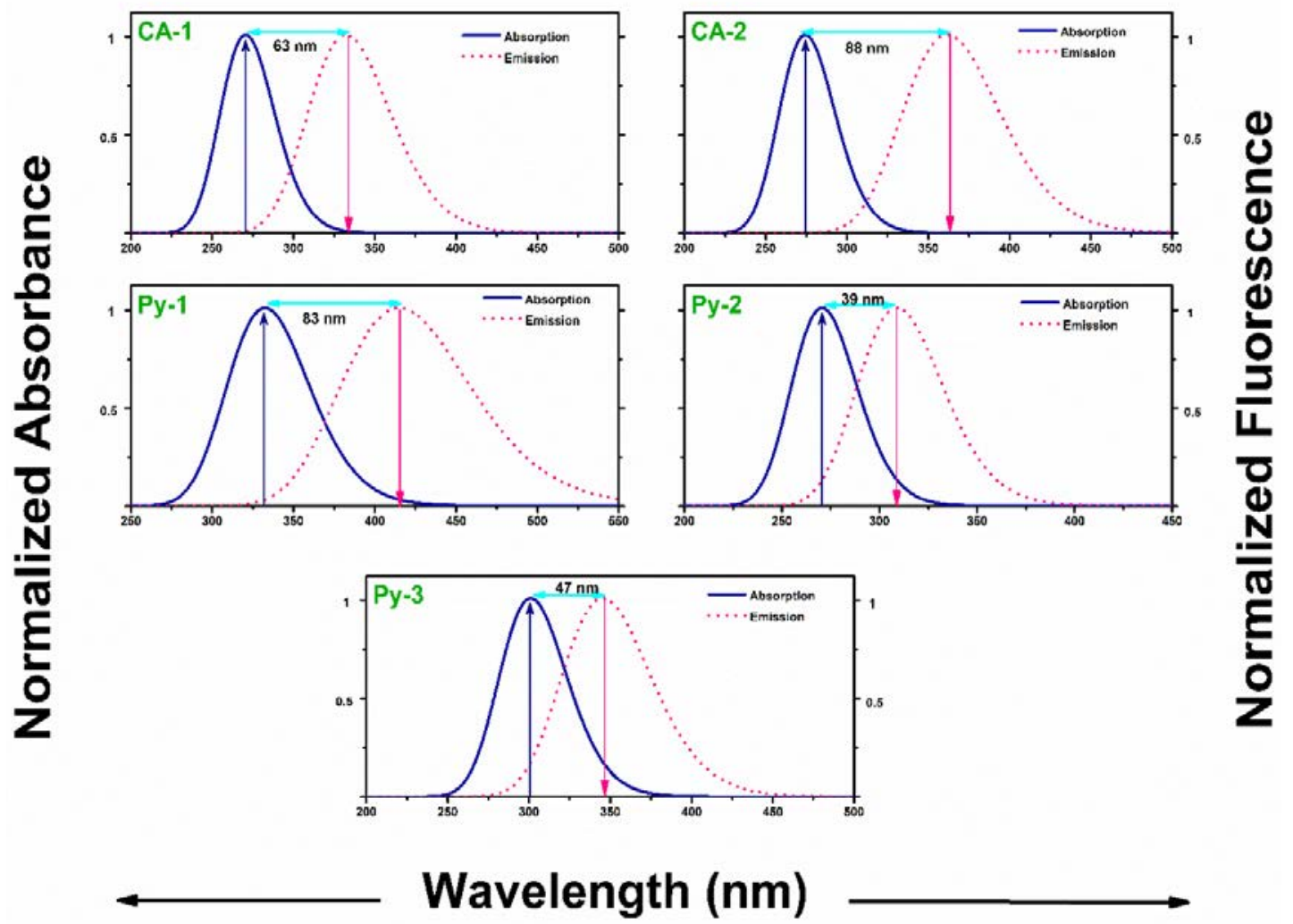

Figure 6. Absorption and emission spectra of the UV-dyes along with the calculated Stokes shift.

\subsection{Intramolecular Charge Transfer Characteristics}

Here, direction of intramolecular charge transfer $(C T)$ that is advantageous to the interfacial electron injection, is examined using Hole-electron analysis module [30] as implemented in Multiwfn 3.8 code. Therein, electron excitations are designated as a process from hole to electron; therefore, graphical analysis and quantitative descriptors are obtainable by this approach. Moreover, the number of excited electron, $\Delta \mathrm{q}\left(\left|e^{-}\right|\right)$, received by the anchoring groups was calculated using interfragment charge transfer (IFCT) method. The results are tabulated in Table 4 . The charge density difference (CDD) between excited state and ground state is estimated as: $\Delta \rho(r)=\rho^{\text {ele }}(r)-\rho^{\text {hole }}(r)$. Figure 7 depicts the visualized isosurface of CDD maps for the excited states studied in Table 2. In which purple and cyan colors are representing the electron and hole distributions, respectively.

Quantitative descriptors of $C T$ involve $D_{C T}\left(\mathrm{~A}^{\circ}\right)$, the $C T$ distance; t-index $\left(\mathrm{A}^{\circ}\right)$, the charge separation degree; $E_{C}(\mathrm{eV})$, the Coulomb attraction energy; and $\mathrm{Sr}(\mathrm{au})$, the holeelectron overlap index.

The charge transfer distance, $D_{C T}$, is calculated as: $D_{C T}=\sqrt{\left|X_{e}-X_{h}\right|^{2}+\left|Y_{e}-Y_{h}\right|^{2}+\left|Z_{e}-Z_{h}\right|^{2}}$ to represent the spatial distance between $C_{\text {hole }}$ and $C_{\text {ele }}$ centroids in $X, Y$ and $Z$ direction. Where $X, Y$ and $Z$ stand for the three-dimensional coordinates of centroids. For example, $X_{e}$ represents the electron density at $X$ orientation with the detailed expression: $X_{e}=\int x \rho^{e l e}(r) d r$ with $\rho^{e l e}(r)$ representing the electron density distribution and $x$ being the $\mathrm{X}$ component of position vector $r$. The charge separation degree in the direction of $C T$, $\mathrm{t}$-index, is calculated by: $\mathrm{t}$ index $=D_{C T}-H_{C T}$, in which $H_{C T}$ is the average degree of spatial extension of hole and electron distribution in $C T$ direction. This means that clear separation of hole and electron distributions is assigned by positive value of $\mathrm{t}$-index. The Coulomb attraction energy, $E_{C}(\mathrm{eV})$, is calculated as follows: 


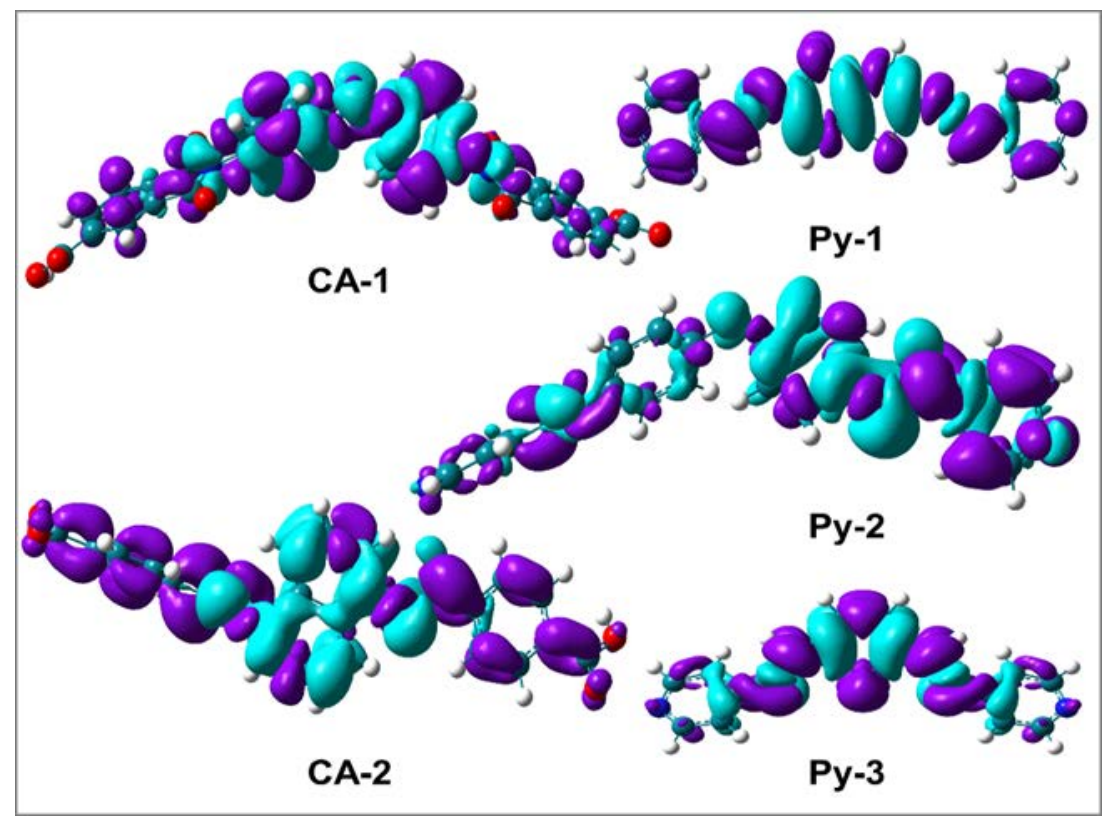

Figure 7. Isosurface of charge density difference (CDD) map. Purple and cyan correspond to electron and hole.

Table 4. Charge transfer descriptors and $\Delta \mathrm{q}$, the net number of charge transferred to the anchor.

\begin{tabular}{cccccc}
\hline Dye & $\boldsymbol{D}_{\boldsymbol{C T}}$ & t-Index & $\boldsymbol{E}_{\boldsymbol{C}}$ & $\boldsymbol{S}_{\boldsymbol{r}}$ & $\boldsymbol{\Delta} \mathbf{q}\left(\mathrm{l} \boldsymbol{e}^{-} \mathrm{I}\right)$ \\
\hline CA-1 & 0.418 & -1.022 & 2.998 & 0.649 & 0.001 \\
CA-2 & 0.678 & -0.575 & 3.211 & 0.572 & 0.050 \\
Py-1 & 0.648 & -0.922 & 3.702 & 0.598 & 0.199 \\
Py-2 & 1.064 & -3.440 & 2.607 & 0.596 & 0.178 \\
Py-3 & 0.172 & -1.102 & 4.430 & 0.746 & 0.013 \\
\hline
\end{tabular}

$E_{C}=\iint \frac{\rho^{\text {hole }}\left(r_{1}\right)-\rho^{\text {ele }}\left(r_{2}\right)}{\left|r_{1}-r_{2}\right|} d r_{1} d r_{2}$, which estimates the required energy for dissociating the photoinduced exciton. The hole-electron overlap index $(S r)$ is calculated as: $S_{r}=\int \sqrt{\rho^{\text {hole }}(r) \rho^{\text {ele }}(r)} d r$, for comparing the overlapping extent of hole and electron. Hence, the theoretical upper limit of $S_{r}$ index is 1 au implying that almost all part of hole and electron distributions are perfectly matched. As presented in Figure 7, photoexcited electron accumulation is clearly observed in anchoring groups of all dyes, except for CA-1 and $\mathrm{Py}-3$. For CA-1, contribution of photoexcited electron to - $\mathrm{COOH}$ anchoring group is negligible, which can be confirmed by the $\Delta \mathrm{q}$ value of $0.001\left|\mathrm{e}^{-}\right|$. Similarly, the isosurface of CDD between S0 and S1 of the Py- 3 dye, spread over the molecule with alternative presentation of the positive part and negative part presented alternatively, assuring the previously predicted local $\pi-\pi^{*}$ excitation of $\mathrm{S} 0 \rightarrow \mathrm{S} 1$ transition.

Generally, it can be seen that hole-electron distribution displayed in the CDD maps (Figure 7) is supported by the numerical calculated data tabulated in Table 4. After photoexcitation, the propitious separation of molecular exciton requires smaller $E_{C}$ to overcome. Consequently, the intramolecular electron-hole (exciton) pair is easier to separate in Py-2 $(2.607 \mathrm{eV})$, whereas the predicted barrier reaches the maximum $(4.430 \mathrm{eV})$ for Py-3, as presented in Table 4. By examining the obtained large values of $S_{r}\left(>0.50 \mathrm{~A}^{\circ}\right)$, the negative values of t-index and small values of $D_{C T}$, one can conclude that the charge separations are not perfect for all the studied dyes. Nevertheless, according to the IFCT analysis for assessing the amount of charge received by the anchoring group, Py- 1 dye with $\Delta \mathrm{q}$ of ca. $0.2\left|e^{-}\right|$is expected to have the largest amount of injected electron into the $C B$ of $\mathrm{TiO}_{2}$, consistently with the order of red-shifted maximum absorption wavelength and improved ability of incident light harvesting. Additionally, the unidirectional intramolecular charge 
transfer $(C T)$ of the $\mathrm{S} 0 \rightarrow \mathrm{S} 1$ electronic transition that is advantageous to the interfacial electron injection, can be observed in CA-2 and Py-1 dyes.

\subsection{Electrochemical Performance of the Dyes}

The ability of a dye to capture incident light (photon) upon photoexcitation, is one of the most crucial factors affecting the overall power conversion efficiency (PCE) of DSC. It can be evaluated by calculating light harvesting efficiency (LHE) according to Equation (1). The estimated values of LHE along with the computed critical energy parameters of the present study are tabulated in Table 5. Since values of oscillator strength (f) obtained from TD-DFT calculations could not reproduce the same trend of experimentally measured absorbance intensities.

Table 5. Estimated light harvesting efficiency (LHF) and critical energy parameters (in eV).

\begin{tabular}{cccccc}
\hline Dye & LHE $^{\boldsymbol{a}}$ & $\boldsymbol{E}_{\boldsymbol{o x}}^{*}$ & $\Delta G_{\boldsymbol{i n j}}$ & $\Delta \boldsymbol{G}_{\boldsymbol{r e g}}$ & $\Delta \boldsymbol{G}_{\text {rec }}$ \\
\hline CA-1 & 0.792 & -2.44 & -1.56 & -2.94 & 3.74 \\
CA-2 & 0.820 & -3.41 & -0.59 & -2.33 & 3.13 \\
Py-1 & 0.971 & -3.66 & -0.34 & -2.21 & 3.01 \\
Py-2 & 0.911 & -2.56 & -1.44 & -2.62 & 3.42 \\
Py-3 & 0.823 & -3.98 & -0.02 & -3.05 & 3.85 \\
\hline
\end{tabular}

${ }^{a}$ LHE calculated with corrected values of oscillator strength according to relative values of the measured absorbance.

Explicitly, the experimental measurements of absorbance showed the following trend: Py-1 $(1.910 \mathrm{au})>$ Py-2 (1.32 au) > Py-3 $(0.94 \mathrm{au}) \cong$ CA-2 $(0.93 \mathrm{au})>$ CA-1 $(0.85 \mathrm{au})$ while theoretically, the intensity of peaks shows the trend CA- $1>\mathrm{Py}-1>\mathrm{Py}-2>\mathrm{Py}-3>\mathrm{CA}-2$, as presented in Table 2 . Therefore, a correct estimation of absorbance intensities obtained from experimental measurements will be used to accurately assess light harvesting efficiency of studied dyes, rather than theoretical attained trend. Accordingly, Py-1 dye recorded the highest LHE value of 0.971 which is consistent with the high perturbation of the charge distribution of the extended conjugation length along molecular backbone. This is reflected in the enlargement of the transition dipole moment of the excited state because the large hole-electron overlap is the precondition of the large transition dipole moment [69]. Conversely, the weakest light harvesting ability is predicted for CA-1 dye.

The thermodynamical feasibility of electron injection and regeneration processes are evaluated by calculating the driving forces, $\Delta_{\text {Ginj }}$ and $\Delta G_{r e g}$, moreover evaluation of $\Delta G_{r e c}$ according to Equations (3)-(5). It is obvious that the negative values of $\Delta G_{i n j}$ for all dyes imply the spontaneity of the electron flow from LUMO of the dye into the $C B$ of $\mathrm{TiO}_{2}$ semiconductor. Similarly, negative values of $\Delta G_{\text {reg }}$ signify the spontaneity of the electron transfer from the reduce redox species in the electrolyte to the oxidized state of dye, i.e., thermodynamically favored regeneration processes. CA-1 dye has the highest negative value $(-1.56 \mathrm{eV})$ of $\Delta G_{i n j}$, implying that it has the greatest energetic driving force of the electron injection. Py-3 dye recorded the highest negative value $(-3.05 \mathrm{eV})$ of $\Delta G_{\text {reg }}$ displaying a very promising driving force for regeneration process. Generally, more negative values of $\Delta G_{r e g}$ than $\Delta G_{i n j}$ values indicates that dye regeneration dynamics is more stable than electron injection [55]. The positive values of $\Delta G_{r e c}$ for all dyes implies that the competing loss electron recombination reaction is nonspontaneous processes in all dyes, which is knowingly crucial for operating DSC.

\subsection{UV-Dyes Adsorbed on $\left(\mathrm{TiO}_{2}\right)_{38}$ Cluster}

To gain deep insight into the interfacial electronic injection process, electronic coupling of the synthesized dyes as adsorbed onto the surface of $\mathrm{TiO}_{2}$ semiconductor is to be simulated. The equilibrium interface geometries are presented in Figure 8. Except for Py-2 dye, its optimized geometry did not converge using the same convergence criteria applied for other dyes so it will be excluded from this analysis. So as to assess the robust interaction and electronic coupling between $\mathrm{TiO}_{2}$ surface and the dyes, the 
adsorption energy $\left(E_{a d s}\right)$ of the studied systems was calculated according to the equation: $E_{a d s}=E_{\left(\mathrm{dye} @ \mathrm{TiO}_{2}\right)}-\left(E_{\mathrm{dye}}+E_{\mathrm{TiO}_{2}}\right)$ where $E_{\mathrm{dye},} E_{\mathrm{TiO}_{2}}$ and $E_{\left(\text {dye } @ \mathrm{TiO}_{2}\right)}$ are energy of isolated dye, bare $\left(\mathrm{TiO}_{2}\right)_{38}$ cluster and dye@ $\left(\mathrm{TiO}_{2}\right)_{38}$ complex, respectively. Critical geometrical parameters of the optimized configurations and the calculated adsorption energies for dye@ $\left(\mathrm{TiO}_{2}\right)_{38}$ are also reported in Figure 8.

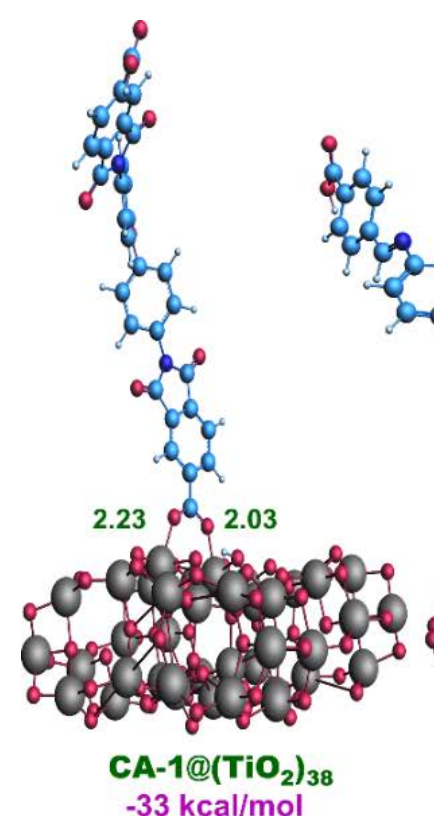

$-33 \mathrm{kcal} / \mathrm{mol}$

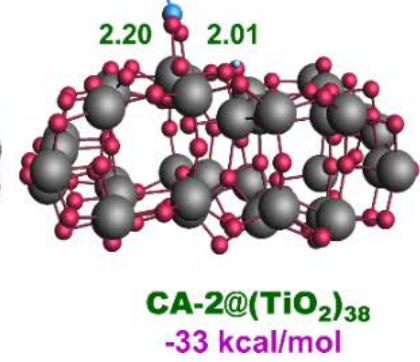

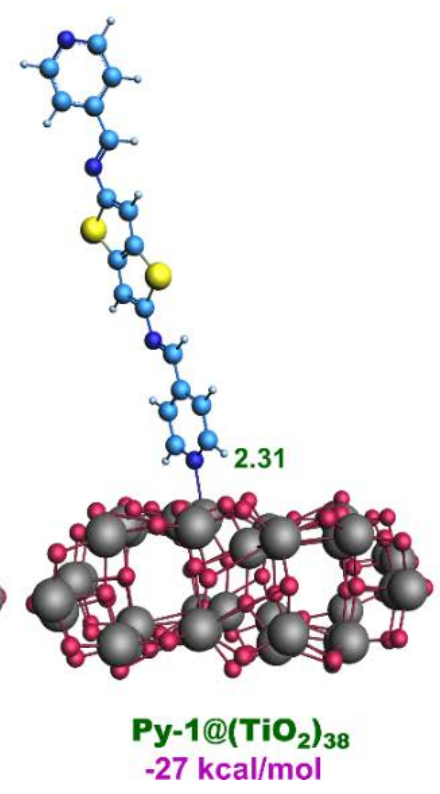

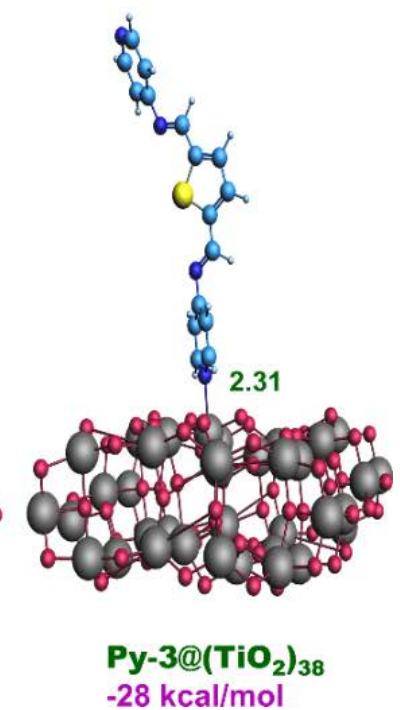

Figure 8. Optimized geometrical configurations of dyes adsorbed onto the surface of (101) anatase $\left(\mathrm{TiO}_{2}\right)_{38}$ cluster along with calculated adsorption energies $(\mathrm{kcal} / \mathrm{mol})$ and the distance from the receptors to the surface of $\mathrm{TiO}_{2}(\mathrm{Ti}-\mathrm{O}$ and $\mathrm{Ti}-\mathrm{N}, \AA)$.

The calculated negative adsorption energies $E_{a d s}$, lying in the range of -27 to $-33 \mathrm{kcal} / \mathrm{mol}$, suggest that adsorption of all dyes is stable and spontaneous. The geometric features of the optimized structures reveal that the dyes stay vertically above the $\mathrm{TiO}_{2}$ cluster surface, with the maximum inclination observed in CA-2 dye. This may allow for relatively faster charge recombination and lower the device efficiency.

The interacting distance between the carbonyl oxygen and the Ti-atom of CA- 1 and CA-2 dyes are 2.23 and $2.20 \AA$, whereas for Py- 1 and Py- 3 dyes, distance between pyridyl nitrogen and Ti is ca. $2.31 \AA$. These critical geometrical parameters support the formation of stable complexes of tightly adsorbed dyes onto the surface of $\mathrm{TiO}_{2}$. Comparing the geometrical parameters of isolated dyes (Table 1) and dyes adsorbed onto $\mathrm{TiO}_{2}$ surface, the twist angle $\left(\Phi_{\mathrm{A} 1}\right)$ of anchoring groups increased to $28^{\circ}, 25^{\circ}$ and $0.2^{\circ}$ for CA-1, CA-2 and Py-1 dyes signifying the steric hindrance variations induced by the adsorption. While $\Phi_{\mathrm{A} 1}$ of adsorbed Py-3 remains as the same $\left(46^{\circ}\right)$ as that of isolated dye. Again, the smallest value $\left(0.2^{\circ}\right)$ of $\Phi_{\mathrm{A} 1}$ of Py-1, predicts that the photoexcited electrons can be efficiently injected into the $\mathrm{TiO}_{2}$ film.

The spatial distribution of FMOs of the dyes @ $\left(\mathrm{TiO}_{2}\right)_{38}$ cluster model with 101 surface was also calculated and displayed in Figure 9. Compared with those (Figure 4) of CA-1, CA-2 and Py-3 dyes, the significant difference in HOMO localized distributions for the dye@ $\mathrm{TiO}_{2}$ systems support the electronic structure variations resulting from electronic coupling between the dyes and $\mathrm{TiO}_{2}$ cluster. Alternatively, electron distribution of LUMO resides in the $\mathrm{TiO}_{2}$ cluster in all the studied systems. This relocation of electron density distribution suggests the charge separation at the dye $/ \mathrm{TiO}_{2}$ interface that is favorable for increasing the electron-transfer rate and enhancing the photoelectric properties. 


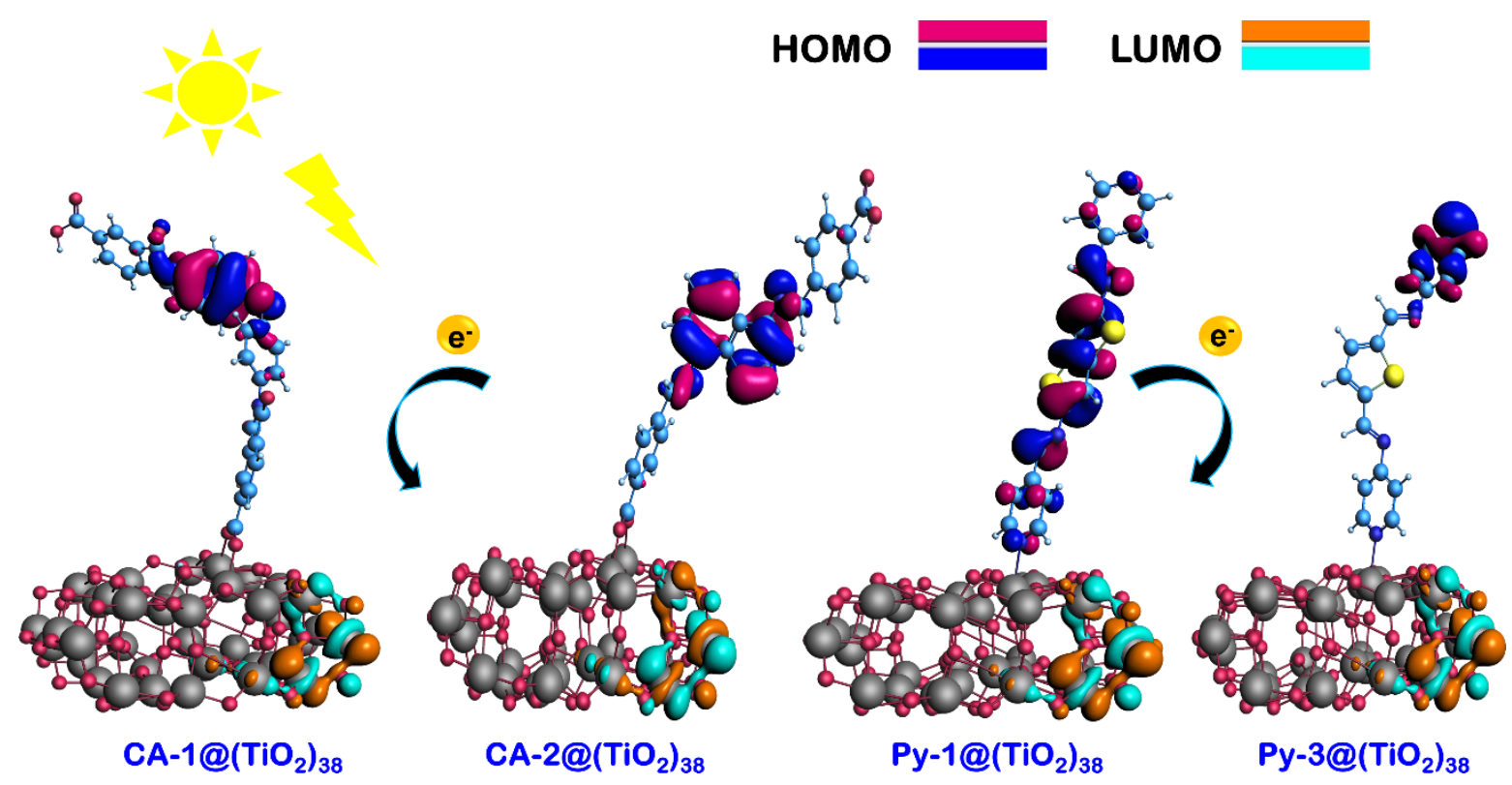

Figure 9. Contour plots of the HOMO and LUMO of the dye adsorbed onto the surface of (101) anatase $\left(\mathrm{TiO}_{2}\right)_{38} \mathrm{cluster}$

All told, the UV-selective organic Py-1 dye (332 nm) can be proposed for potential cosensitization for the NIR-selective VG20 $(825 \mathrm{~nm})$ dye-sensitized solar cell. Among the five synthesized UV-selective organic dyes, Py-1 dye exhibits the most advantageous structural attributes for sensitization, has the longest conjugation length; attains the basic required energetics of operating DSCs, possesses the smallest HOMO-LUMO energy gap and shows the greatest accepting power of pyridine anchoring group. Additionally, it has the most intense emission band with large Stokes shift, demonstrates stable and spontaneous adsorption onto surface of $\mathrm{TiO}_{2}$, has an accepted distribution of FMOs electron densities either as free dye or adsorbate, and displays thermodynamical spontaneity of electron injection and dye regeneration processes. Most importantly, Py-1 dye achieves the complementarity of absorption spectrum with the largest hyperchromic shift and a broad absorption band in the near-UV subregion corresponding to $\mathrm{S} 0 \rightarrow \mathrm{S} 1$ electronic transition and $\mathrm{HOMO} \rightarrow \mathrm{LUMO}$ as dominant configuration. In addition to the predicted largest amount of charge received by the anchoring group, the Py- 1 dye absorption band was assigned as hybridized $C T$ and local $\pi-\pi^{*}$ excitation (HLCT), which could generate synergistic enhancement effects for the $C T$ process [70,71].

Furthermore, we chose the Py-1 dye because it features the highest value of measured absorptivity and computed light harvesting efficiency, therefore, the performance of the VG20-based transparent cell can be improved, as thinner film is often employed for high molar absorptivity dyes. The small molecular size of Py-1, relative to VG20 dye, can also minimize the dyes competitive adsorption issues. Above all, the UV-absorber Py-1 and the NIR-absorber VG20 have pyridine and $-\mathrm{COOH}$ as anchoring groups, respectively. This is a known strategy to overcome the competitive adsorption due to cosensitization, namely by combining dyes with pyridyl and carboxyl anchoring groups that respectively prefer Lewis- and Bronsted-acidic anchoring sites on $\mathrm{TiO}_{2}$. The advantage of the optical complementarity and the different $\mathrm{TiO}_{2}$-adsorption-site selectivity of Py-1 and VG20, can be accomplished accordingly.

\subsection{Electronic Structure of Py-1/VG20 Cosensitizer}

Electronic incompatibility of cosensitizers is one of the foremost reasons of depleting the photovoltaic (PV) performance of DSCs upon cosensitization. Consequently, the electronic structure of the proposed cosensitizer Py-1/VG20 was calculated, in order to inspect if they are chemically compatible with each other. The obtained equilibrium 
geometry of Py-1/VG20 dimer is displayed in Figure 10a. It was found that the interlayer distance is ca. $3.9 \AA$ of superimposed Py-1/VG20 structure.
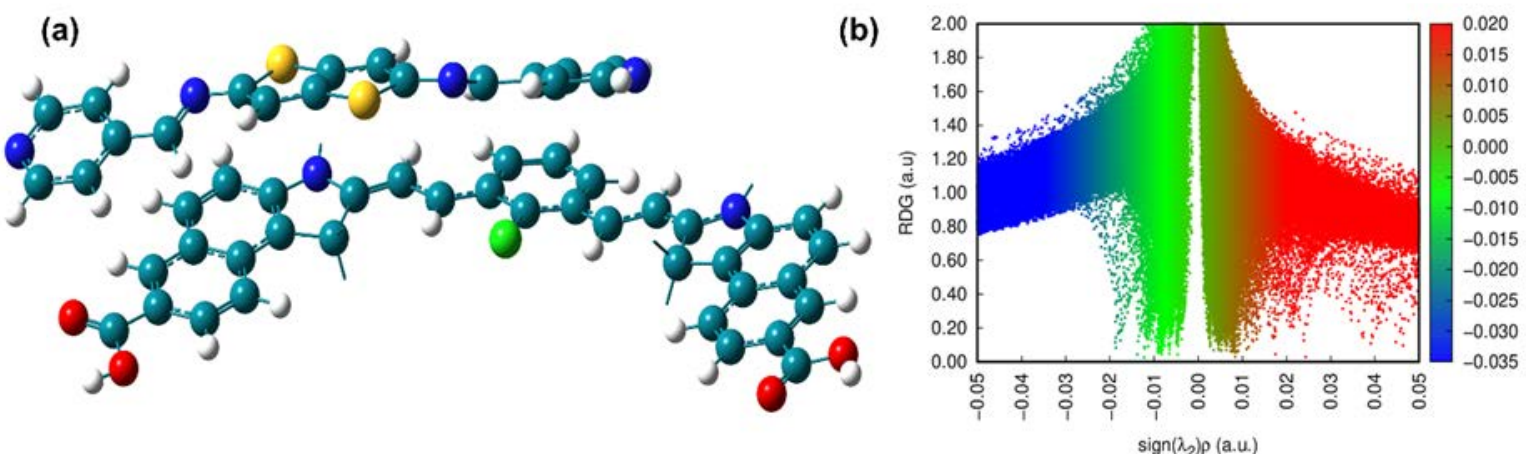

(c)

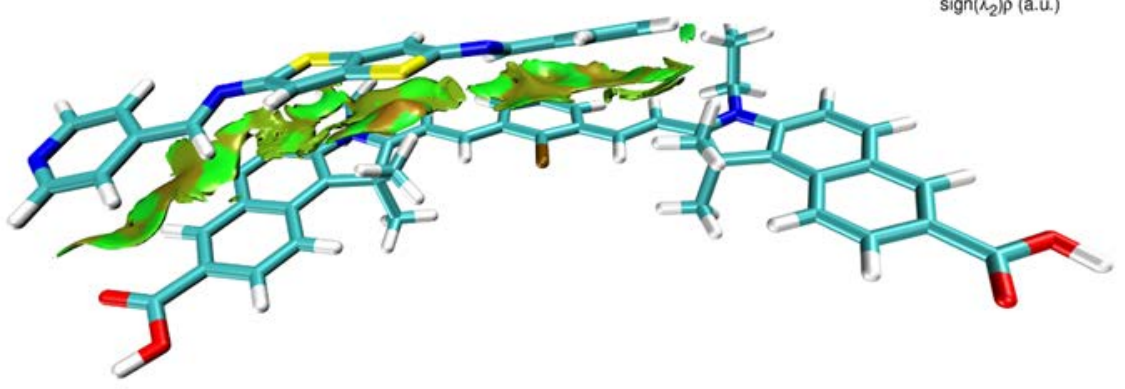

Figure 10. (a) Optimized geometry. (b) Scatter map of RDG versus electron density $\rho(r)$ multiplied by the sign of second Hessian eigenvalue $\lambda_{2}$, (c) RDG isosurface map for the Py-1/VG20 dimer.

Quantitative assessment of the stability of dimer involves calculation of total interaction energy $\Delta E_{\text {tot }}$ followed by simple energy decomposition analysis (EDA). Calculated value of $\Delta E_{\text {tot }}$ is $-38.07 \mathrm{kcal} / \mathrm{mol}$, was obtained via the expression $\Delta E_{\text {tot }}=E_{\text {dimer }}-\sum_{i} E_{i}^{\text {frag }}$. In simple EDA, the total energy variation of forming a dimer is decomposed as: $\Delta E_{\text {tot }}=\Delta E_{\text {orb }}+\Delta E_{\text {steric }}+\Delta E_{\text {disp. }}$. Here, $\Delta E_{\text {disp }}$ is the dispersion interaction (vdW) energy evaluated as $\Delta E_{\text {disp }}=E_{\mathrm{tot}}^{\mathrm{DFT}-\mathrm{D} 3}-E_{\mathrm{tot}}^{\mathrm{DFT}}$, in which the D3 Grimme's correction is to account for the dispersion energy that is missing in DFT energy. It was found that $\Delta E_{\text {disp }}=-5.012 \mathrm{kcal} / \mathrm{mol}$, which means the dispersion weak intermolecular attractive interaction stabilizes the formation of Py-1/VG20 dimer. The steric energy ( $\left.\Delta E_{\text {steric }}\right)$ is the sum of the electrostatic energy, the exchange-correlation energy and the exchangerepulsion (Pauli) term. For the studied dimer, $\Delta E_{\text {steric }}$ was found to be $-17.68 \mathrm{kcal} / \mathrm{mol}$, implying that electrostatic energy possesses high attractive contributions, since the Pauli term is invariably positive corresponding to the repulsive interaction between the electrons in occupied orbitals of monomers. Calculated $\Delta E_{\text {orb }}$ of $-15.38 \mathrm{kcal} / \mathrm{mol}$ is the orbital interaction energy between the monomers implying a strong attraction originated from the overlap of orbitals between Py-1 and VG20 monomers and stabilizes the formation of the dimer.

Overall, the total interaction energy, $\Delta E_{\text {tot }}$ of $-38.07 \mathrm{kcal} / \mathrm{mol}$, indicates that the formation of Py-1/VG20 dimer is favored by the steric, electrostatic, as well as orbital interactions. Figure $10 \mathrm{~b}$ depicts the plot of reduced density gradient (RDG) versus $\operatorname{sign}\left(\lambda_{2}\right) \rho$, the sign of second Hessian eigenvalue $\left(\lambda_{2}\right)$ multiplied by electron density $\rho(r)$. Therein, electron density $\rho(r)$ defines the strength of interactions; namely low $\rho(r)$ regions are related to the dispersion or vdW weak interactions (green dots) and high $\rho(r)$ regions related to stronger interactions, either stabilizing attractive $\left(\lambda_{2}<0\right)$ such as H-bonds (blue dots) or destabilizing repulsive $\left(\lambda_{2}>0\right)$ such as steric (red dots) interactions. As shown in Figure 10b, the spike at the negative part with low-density $(\rho(r) \approx 0)$, low-gradient $(\mathrm{RDG}<0.5 \mathrm{au})$ approves the calculated stabilizing $\mathrm{vdW}$ attraction energy $\Delta E_{\text {disp }}$ of $-5.012 \mathrm{kcal} / \mathrm{mol}$. Additionally, low-gradient (RDG $<0.5 \mathrm{au}$ ) blue dots at $\operatorname{sign}\left(\lambda_{2}\right) \rho(r)$ of ca. $-0.025 \mathrm{au}$ indicates the presence of the stabilizing $\mathrm{H}$-bonding interaction in the studied dimer. 
Visualization of the physical origin of the calculated noncovalent interactions is attainable by observing RDG isosurface map, Figure 10c. Therein, the isosurface is colored on a blue-green-red scale according to values of sign $\left(\lambda_{2}\right) \rho$ function. The intramolecular interactions were screened out for clear displaying of intermolecular interactions only. Despite the existence of low-gradient spikes (red dots) in the positive region of Figure 10b, demonstrating the occurrence of destabilizing steric repulsion, the lack of red isosurface extending between two monomers in Figure 10c implies that these steric effects are exhibited within the rings. The green isosurface in Figure 10c shows clearly the extending weak vdW attractive interaction regions between Py-1 and VG20 monomers. Considering the calculated low destabilizing energy and the high stabilizing orbital, $\mathrm{vdW}$ and electrostatic attractive interactions of the studied dimer, we could argue that Py-1 and VG20 dyes are chemically compatible and this dimer is applicable for cosensitization in DSCs.

\section{Conclusions}

In this work, novel diimide and Schiff bases UV-absorbers have been synthesized by introducing carboxyl and pyridyl anchoring groups to be applied in transparent dyesensitized solar cells. UV/Vis absorption spectra of solution-based free dyes were measured experimentally. A systematic ground state and excited state investigation was subsequently carried out via DFT and TD-DFT approaches. The dye@ $\mathrm{TiO}_{2}$ interface was examined via further in silico calculations. Energetics of the studied dyes, either isolated or adsorbed onto $\mathrm{TiO}_{2}$ surface, addition to the optical properties and estimated photovoltaic performance, showed that they function well in in DSCs. The pyridyl-containing Py-1 dye, with thienothiophene core, unquestionably outperforms the other studied dyes. In particular, exhibiting the most advantageous structural attributes for sensitization with the most conjugated fragments. Its pyridine anchor exerted the greatest accepting power thus, received the largest amount of calculated transferred charge. Moreover, Py-1 showed an increase of measured absorption and calculated emission intensities with large Stokes shift. This high absorptivity boosts the light harvesting efficiency, which is crucially required in transparent DSCs incorporating sufficiently thin layer of $\mathrm{TiO}_{2}$ in order to not be seen. Accordingly, the UV-absorber Py- 1 was tested for cosensitization of the NIR-absorber VG20- $C_{2}$. The electronic structure of the Py-1/VG20 dimer was examined via calculated interaction energy, energy decomposition analysis, and reduced density gradient maps. Results showed the chemical compatibility of the proposed cosensitizers with low destabilizing repulsive interactions moreover high stabilizing orbital, $\mathrm{vdW}$ and electrostatic attractive interactions. This is in addition to the small molecular size of Py-1, relative to VG20 dye, which is critically needed to minimize the problematic dyes competitive adsorption. Above all, the judicious choice of Py-1 as a cosensitizer for VG20 follows the known strategy of combining cosensitizers with pyridyl and carboxyl anchoring groups for respectively selecting Lewis- and Brønsted-acidic different anchoring sites on $\mathrm{TiO}_{2}$. As a consequence, this study suggests the promising application of UV-absorber Py-1 along with the NIR-absorber VG20 in transparent dye-sensitized solar cells of higher power conversion efficiency.

Supplementary Materials: The following are available online. Figure S1: optimized geometries of the ground state of the studied dyes, Figure S2: major contributing molecular orbitals in the studied electronic transitions, Figure S3: optimized geometries of the excited state of studied dyes, Figure S4: ${ }^{1}$ HNMR spectrum of compound CA-1, Figure S5: ${ }^{13}$ CNMR spectrum of compound CA-1, Figure S6: ${ }^{1} \mathrm{HNMR}$ spectrum of compound CA-2, Figure S7: ${ }^{1} \mathrm{HNMR}$ spectrum of compound Py-1.

Author Contributions: Conceptualization, E.N.; supervision, A.A.H.; validation, A.A.H. and M.H.; methodology, E.N.; formal analysis, M.Z. and E.N.; investigation, M.H.; data curation, R.B.A., E.N., S.P., M.H., M.Z. and A.A.H.; visualization, E.N.; writing-original draft preparation, E.N. and M.H.; writing-review and editing, A.A.H., E.N., M.H., M.Z. and R.B.A.; project administration, R.B.A. and S.P.; funding acquisition, M.H. and E.N. All authors have read and agreed to the published version of the manuscript. 
Funding: This research work was funded by the Deputyship for Research \& Innovation, Ministry of Education in Saudi Arabia, the project number (442/47).

Data Availability Statement: Raw data are available upon request.

Acknowledgments: The authors extend their appreciation to the Deputyship for Research \& Innovation, Ministry of Education in Saudi Arabia for funding this research work, the project number (442/47). Additionally, the authors would like to extend their appreciation to Taibah University for its supervision support.

Conflicts of Interest: The authors declare that they have no known competing financial interests or personal relationships that could have appeared to influence the work reported in this paper.

Sample Availability: Data is available in this article and Supplementary Materials.

\section{References}

1. Pagliaro, M.; Ciriminna, R.; Palmisano, G. BIPV: Merging the photovoltaic with the construction industry. Prog. Photovolt. Res. Appl. 2010, 18, 61-72. [CrossRef]

2. Yoo, K.; Kim, J.-Y.; Lee, J.A.; Kim, J.S.; Lee, D.-K.; Kim, K.; Kim, J.Y.; Kim, B.; Kim, H.; Kim, W.M. Completely transparent conducting oxide-free and flexible dye-sensitized solar cells fabricated on plastic substrates. ACS Nano 2015, 9, 3760-3771. [CrossRef]

3. Selvaraj, P.; Ghosh, A.; Mallick, T.K.; Sundaram, S. Investigation of semi-transparent dye-sensitized solar cells for fenestration integration. Renew. Energy 2019, 141, 516-525. [CrossRef]

4. Yoon, S.; Tak, S.; Kim, J.; Jun, Y.; Kang, K.; Park, J. Application of transparent dye-sensitized solar cells to building integrated photovoltaic systems. Build. Environ. 2011, 46, 1899-1904. [CrossRef]

5. O'regan, B.; Grätzel, M. A low-cost, high-efficiency solar cell based on dye-sensitized colloidal $\mathrm{TiO}_{2}$ films. Nature 1991, 353 , 737-740. [CrossRef]

6. Al Mogren, M.M.; Ahmed, N.M.; Hasanein, A.A. Molecular modeling and photovoltaic applications of porphyrin-based dyes: A review. J. Saudi Chem. Soc. 2020, 24, 303-320. [CrossRef]

7. Listorti, A.; O'regan, B.; Durrant, J.R. Electron transfer dynamics in dye-sensitized solar cells. Chem. Mater. 2011, 23, 3381-3399. [CrossRef]

8. Cole, J.M.; Pepe, G.; Al Bahri, O.K.; Cooper, C.B. Cosensitization in dye-sensitized solar cells. Chem. Rev. 2019, $119,7279-7327$. [CrossRef] [PubMed]

9. Zuo, L.; Shi, X.; Fu, W.; Jen, A.K.Y. Highly efficient semitransparent solar cells with selective absorption and tandem architecture. Adv. Mater. 2019, 31, 1901683. [CrossRef]

10. Aghazada, S.; Nazeeruddin, M.K. Ruthenium complexes as sensitizers in dye-sensitized solar cells. Inorganics $2018,6,52$. [CrossRef]

11. Xie, X.; Sun, D.; Wei, Y.; Yuan, Y.; Zhang, J.; Ren, Y.; Wang, P. Thienochrysenocarbazole based organic dyes for transparent solar cells with over 10\% efficiency. J. Mater. Chem. A 2019, 7, 11338-11346. [CrossRef]

12. Wu, H.; Zhang, J.; Ren, Y.; Zhang, Y.; Yuan, Y.; Shen, Z.; Li, S.; Wang, P. Tuning the Color Palette of Semi-Transparent Solar Cells via Lateral $\pi$-Extension of Polycyclic Heteroaromatics of Donor-Acceptor Dyes. ACS Appl. Energy Mater. 2020, 3, 4549-4558. [CrossRef]

13. Huaulmé, Q.; Mwalukuku, V.M.; Joly, D.; Liotier, J.; Kervella, Y.; Maldivi, P.; Narbey, S.; Oswald, F.; Riquelme, A.J.; Anta, J.A.; et al. Photochromic dye-sensitized solar cells with light-driven adjustable optical transmission and power conversion efficiency. Nat. Energy 2020, 5, 468-477. [CrossRef]

14. Zhang, K.; Qin, C.; Yang, X.; Islam, A.; Zhang, S.; Chen, H.; Han, L. High-performance, transparent, dye-sensitized solar cells for see-through photovoltaic windows. Adv. Energy Mater. 2014, 4, 1301966. [CrossRef]

15. Naim, W.; Novelli, V.; Nikolinakos, I.; Barbero, N.; Dzeba, I.; Grifoni, F.; Ren, Y.; Alnasser, T.; Velardo, A.; Borrelli, R.; et al. Transparent and Colorless Dye-Sensitized Solar Cells Exceeding 75\% Average Visible Transmittance. JACS Au 2021, 1, $409-426$. [CrossRef] [PubMed]

16. Wang, Z.; Zhu, X.; Zhang, S.; Xu, L.; Zhao, Z.; He, G. Twisted Biphenyl-Diimide Derivatives with Aggregation-Induced Emission and Thermally Activated Delayed Fluorescence for High Performance OLEDs. Adv. Opt. Mater. 2021, 9, 2001764. [CrossRef]

17. Maniam, S.; Higginbotham, H.F.; Bell, T.D.; Langford, S.J. Harnessing brightness in naphthalene diimides. Chem. Eur. J. 2019, 25, 7044-7057. [CrossRef]

18. Cao, Q.; Crawford, D.E.; Shi, C.; James, S.L. Greener Dye Synthesis: Continuous, Solvent-Free Synthesis of Commodity Perylene Diimides by Twin-Screw Extrusion. Angew. Chem. Int. Ed. 2020, 59, 4478-4483. [CrossRef]

19. Zhan, X.; Facchetti, A.; Barlow, S.; Marks, T.J.; Ratner, M.A.; Wasielewski, M.R.; Marder, S.R. Rylene and related diimides for organic electronics. Adv. Mater. 2011, 23, 268-284. [CrossRef] [PubMed]

20. Kozma, E.; Catellani, M. Perylene diimides based materials for organic solar cells. Dyes Pigment. 2013, 98, 160-179. [CrossRef]

21. Cimerman, Z.; Miljanić, S.; Galić, N. Schiff bases derived from aminopyridines as spectrofluorimetric analytical reagents. Croat. Chem. Acta 2000, 73, 81-95. 
22. Schiff, H. Mittheilungen aus dem Universitätslaboratorium in Pisa: Eine neue Reihe organischer Basen. Justus Liebigs Ann. Chem. 1864, 131, 118-119. [CrossRef]

23. Jeevadason, A.W.; Murugavel, K.K.; Neelakantan, M. Review on Schiff bases and their metal complexes as organic photovoltaic materials. Renew. Sustain. Energy Rev. 2014, 36, 220-227. [CrossRef]

24. Zhao, Y.; Truhlar, D.G. The M06 suite of density functionals for main group thermochemistry, thermochemical kinetics, noncovalent interactions, excited states, and transition elements: Two new functionals and systematic testing of four M06-class functionals and 12 other functionals. Theor. Chem. Acc. 2008, 120, 215-241.

25. Krishnan, R.; Binkley, J.S.; Seeger, R.; Pople, J.A. Self-consistent molecular orbital methods. XX. A basis set for correlated wave functions. J. Chem. Phys. 1980, 72, 650-654. [CrossRef]

26. Madhusudhanan, M.C.; Balan, H.; Werz, D.B.; Sureshan, K.M. Azide...Oxygen Interaction: A Crystal Engineering Tool for Conformational Locking. Angew. Chem. Int. Ed. 2021, 60, 22797-22803. [CrossRef]

27. Bauernschmitt, R.; Ahlrichs, R. Treatment of electronic excitations within the adiabatic approximation of time dependent density functional theory. Chem. Phys. Lett. 1996, 256, 454-464. [CrossRef]

28. Frisch, M.J.; Trucks, G.W.; Schlegel, H.B.; Scuseria, G.E.; Robb, M.A.; Cheeseman, J.R.; Scalmani, G.; Barone, V.; Mennucci, B.; Petersson, G.A.; et al. Gaussian 09; Revision D.01; Gaussian. Inc.: Wallingford, UK, 2013.

29. Lu, T.; Chen, F. Multiwfn: A multifunctional wavefunction analyzer. J. Comput. Chem. 2012, 33, 580-592. [CrossRef]

30. Liu, Z.; Lu, T.; Chen, Q. An sp-hybridized all-carboatomic ring, cyclo[18]carbon: Electronic structure, electronic spectrum, and optical nonlinearity. Carbon 2020, 165, 461-467. [CrossRef]

31. Lundqvist, M.J.; Nilsing, M.; Persson, P.; Lunell, S. DFT study of bare and dye-sensitized $\mathrm{TiO}_{2}$ clusters and nanocrystals. Int. J. Quantum Chem. 2006, 106, 3214-3234. [CrossRef]

32. Te Velde, G.t.; Bickelhaupt, F.M.; Baerends, E.J.; Fonseca Guerra, C.; van Gisbergen, S.J.; Snijders, J.G.; Ziegler, T. Chemistry with ADF. J. Comput. Chem. 2001, 22, 931-967. [CrossRef]

33. Rüger, S.R.; Franchini, M.; Trnka, T.; Yakovlev, A.; van Lenthe, E.; Philipsen, P.; van Vuren, T.; Klumpers, B.; Soini, T. AMS 2020, Theoretical Chemistry, Vrije Universiteit, Amsterdam, The Netherlands. Available online: http:/ /www.scm.com (accessed on 17 April 2021).

34. Van Lenthe, E.; Ehlers, A.; Baerends, E.-J. Geometry optimizations in the zero order regular approximation for relativistic effects. J. Chem. Phys. 1999, 110, 8943-8953. [CrossRef]

35. Perdew, J.P.; Burke, K.; Ernzerhof, M. Generalized gradient approximation made simple. Phys. Rev. Lett. 1996, 77, 3865. [CrossRef] [PubMed]

36. Van Lenthe, E.; Baerends, E.J. Optimized Slater-type basis sets for the elements 1-118. J. Comput. Chem. 2003, 24, 1142-1156. [CrossRef] [PubMed]

37. Lu, T. Molclus Program, Version 1.9. 2019. Available online: http://www.keinsci.com/research/molclus.html (accessed on 6 December 2019).

38. Stewart, J.J.P. MOPAC2016; Stewart Computational Chemistry: Colorado Springs, CO, USA, 2016.

39. Stewart, J.J.P. Optimization of parameters for semiempirical methods VI: More modifications to the NDDO approximations and re-optimization of parameters. J. Mol. Model. 2013, 19, 1-32. [CrossRef] [PubMed]

40. Grimme, S.; Antony, J.; Ehrlich, S.; Krieg, H. A consistent and accurate ab initio parametrization of density functional dispersion correction (DFT-D) for the 94 elements H-Pu. J. Chem. Phys. 2010, 132, 154104. [CrossRef] [PubMed]

41. Johnson, E.R.; Keinan, S.; Mori-Sánchez, P.; Contreras-García, J.; Cohen, A.J.; Yang, W. Revealing Noncovalent Interactions. J. Am. Chem. Soc. 2010, 132, 6498-6506. [CrossRef] [PubMed]

42. Humphrey, W.; Dalke, A.; Schulten, K. VMD: Visual molecular dynamics. J. Mol. Gr. 1996, 14, 33-38. [CrossRef]

43. Borlido, P.; Aull, T.; Huran, A.W.; Tran, F.; Marques, M.A.L.; Botti, S. Large-Scale Benchmark of Exchange-Correlation Functionals for the Determination of Electronic Band Gaps of Solids. J. Chem. Theory Comput. 2019, 15, 5069-5079. [CrossRef]

44. Becke, A.D. A new mixing of Hartree-Fock and local density-functional theories. J. Chem. Phys. 1993, 98, 1372-1377. [CrossRef]

45. Yanai, T.; Tew, D.P.; Handy, N.C. A new hybrid exchange-correlation functional using the Coulomb-attenuating method (CAM-B3LYP). Chem. Phys. Lett. 2004, 393, 51-57. [CrossRef]

46. Peverati, R.; Truhlar, D.G. Improving the accuracy of hybrid meta-GGA density functionals by range separation. J. Phys. Chem. Lett. 2011, 2, 2810-2817. [CrossRef]

47. Chai, J.-D.; Head-Gordon, M. Long-range corrected hybrid density functionals with damped atom-atom dispersion corrections Phys. Chem. Chem. Phys. 2008, 10, 6615-6620. [CrossRef] [PubMed]

48. Henderson, T.M.; Izmaylov, A.F.; Scalmani, G.; Scuseria, G.E. Can short-range hybrids describe long-range-dependent properties? J. Chem. Phys. 2009, 131, 044108. [CrossRef] [PubMed]

49. Krukau, A.V.; Vydrov, O.A.; Izmaylov, A.F.; Scuseria, G.E. Influence of the exchange screening parameter on the performance of screened hybrid functionals. J. Chem. Phys. 2006, 125, 224106. [CrossRef] [PubMed]

50. Peverati, R.; Truhlar, D.G. Screened-exchange density functionals with broad accuracy for chemistry and solid-state physics. Phys. Chem. Chem. Phys. 2012, 14, 16187-16191. [CrossRef]

51. Henderson, T.M.; Izmaylov, A.F.; Scuseria, G.E.; Savin, A. The importance of middle-range Hartree-Fock-type exchange for hybrid density functionals. J. Chem. Phys. 2007, 127, 221103. [CrossRef] [PubMed] 
52. Henderson, T.M.; Izmaylov, A.F.; Scuseria, G.E.; Savin, A. Assessment of a middle-range hybrid functional. J. Chem. Theory Comput. 2008, 4, 1254-1262. [CrossRef] [PubMed]

53. Staroverov, V.N.; Scuseria, G.E.; Tao, J.; Perdew, J.P. Comparative assessment of a new nonempirical density functional: Molecules and hydrogen-bonded complexes. J. Chem. Phys. 2003, 119, 12129-12137. [CrossRef]

54. Boese, A.D.; Handy, N.C. New exchange-correlation density functionals: The role of the kinetic-energy density. J. Chem. Phys. 2002, 116, 9559-9569. [CrossRef]

55. Roy, J.K.; Kar, S.; Leszczynski, J. Revealing the Photophysical Mechanism of N,N'-Diphenyl-aniline Based Sensitizers with the D-D- $\pi-A$ Framework: Theoretical Insights. ACS Sustain. Chem. Eng. 2020, 8, 13328-13341. [CrossRef]

56. Xu, B.; Li, Y.; Song, P.; Ma, F.; Sun, M. Photoactive layer based on T-shaped benzimidazole dyes used for solar cell: From photoelectric properties to molecular design. Sci. Rep. 2017, 7, 1-17.

57. Zhou, S.-Q.; Xia, Q.-Y.; Kong, L.-X.; Ayyanar, K.; Ju, X.-H. Theoretical Study of Effects of Anchoring Groups on Photovoltaic Properties of a Triarylamine-Based p-Type Sensitizer. ACS Omega 2020, 5, 23491-23496. [CrossRef] [PubMed]

58. Zhang, W.; Wang, L.; Mao, L.; Jiang, J.; Ren, H.; Heng, P.; Ågren, H.; Zhang, J. Computational protocol for precise prediction of dye-sensitized solar cell performance. J. Phys. Chem. C 2020, 124, 3980-3987. [CrossRef]

59. Kesavan, R.; Attia, F.; Su, R.; Anees, P.; El-Shafei, A.; Adhikari, A.V. Asymmetric Dual Anchoring Sensitizers/Cosensitizers for Dye Sensitized Solar Cell Application: An Insight into Various Fundamental Processes inside the Cell. J. Phys. Chem. C 2019, 123, 24383-24395. [CrossRef]

60. Roy, J.K.; Kar, S.; Leszczynski, J. Insight into the optoelectronic properties of designed solar cells efficient tetrahydroquinoline dye-sensitizers on TiO 2 (101) surface: First principles approach. Sci. Rep. 2018, 8, 1-12. [CrossRef] [PubMed]

61. Gao, Y.; Guan, W.; Yan, L.-K.; Su, Z.-M. A theoretical investigation on promising acceptor groups for POM-based dyes: From electronic structure to photovoltaic conversion efficiency. J. Mater. Chem. C 2020, 8, 219-227. [CrossRef]

62. Majid, A.; Sana, M.; Khan, S.U.D.; Ahmad, N. Time-dependent density functional theory investigations on structural modification in carbazole-based organic photosensitizers to improve electron injection in dye-sensitized solar cell. Int. J. Quantum Chem. 2020, 120, e26253. [CrossRef]

63. Liu, H.; Liu, L.; Fu, Y.; Liu, E.; Xue, B. Theoretical Design of D- $\pi-A-A$ Sensitizers with Narrow Band Gap and Broad Spectral Response Based on Boron Dipyrromethene for Dye-Sensitized Solar Cells. J. Chem. inf. Model. 2019, 59, 2248-2256. [CrossRef]

64. Tsai, H.-H.G.; Tan, C.-J.; Tseng, W.-H. Electron transfer of squaraine-derived dyes adsorbed on $\mathrm{TiO}_{2}$ clusters in dye-sensitized solar cells: A density functional theory investigation. J. Phys. Chem. C 2015, 119, 4431-4443. [CrossRef]

65. Al-Harrasi, Y.; Al-Hadhrami, S.A.; Varghese, B.; Busafi, S.N.A.; Suliman, F.O.; Al Kindy, S.M. Experimental and theoretical insights into the enhanced intramolecular charge transfer fluorescence of a $3(2 \mathrm{H})$-furanone based $\mathrm{d}$ - $\pi$-A compounds tailored with dialkyl chains. J. Mol. Struct. 2021, 1239, 130500. [CrossRef]

66. Samanta, P.N.; Majumdar, D.; Roszak, S.; Leszczynski, J. First-principles approach for assessing cold electron injection efficiency of dye-sensitized solar cell: Elucidation of mechanism of charge injection and recombination. J. Phys. Chem. C 2020, 124, 2817-2836. [CrossRef]

67. Xu, B.; Li, Y.; Song, P.; Ma, F.; Yang, Y. Significant Improvements of Near-IR Absorption, Electron Injection, and Oxidized Regeneration on Organic Sensitizers for Solar Cells. J. Phys. Chem. C 2021, 125, 13109-13122. [CrossRef]

68. Nabil, E.; Hasanein, A.A.; Alnoman, R.B.; Zakaria, M. Optimizing the Cosensitization Effect of SQ02 Dye on BP-2 Dye-Sensitized Solar Cells: A Computational Quantum Chemical Study. J. Chem. Inf. Model. 2021, 61, 5098-5116. [CrossRef] [PubMed]

69. Liu, Z.; Lu, T. Optical properties of novel conjugated nanohoops: Revealing the effects of topology and size. J. Phys. Chem. C 2020, 124, 7353-7360. [CrossRef]

70. Xu, P.; Zhang, C.-R.; Wu, Y.-Z.; Yuan, L.-H.; Chen, Y.-H.; Liu, Z.-J.; Chen, H.-S. Fusing Thienyl with N-Annulated Perylene Dyes and Photovoltaic Parameters for Dye-Sensitized Solar Cells. J. Phys. Chem. A 2020, 124, 3626-3635. [CrossRef] [PubMed]

71. Zhou, C.; Cong, D.; Gao, Y.; Liu, H.; Li, J.; Zhang, S.; Su, Q.; Wu, Q.; Yang, B. Enhancing the Electroluminescent Efficiency of Acridine-Based Donor-Acceptor Materials: Quasi-Equivalent Hybridized Local and Charge-Transfer State. J. Phys. Chem. C 2018, 122, 18376-18382. [CrossRef] 